\title{
Comparison of nitrous acid detection using open-path incoherent broadband cavity-enhanced absorption spectroscopy and extractive long-path absorption photometry
}

\author{
Sophie Dixneuf $^{1 \S}$, Albert A. Ruth ${ }^{1 *}$, (the late) Rolf Häseler ${ }^{2+}$, (the late) Theo Brauers ${ }^{2 \text { 少, }}$
}

5 Franz Rohrer ${ }^{2}$, and Hans-Peter Dorn ${ }^{2}$

${ }^{1}$ Department of Physics \& Environmental Research Institute, University College Cork, Cork, Ireland.

${ }^{2}$ Institut für Energie und Klimaforschung, IEK-8: Troposphäre, Forschungszentrum Jülich GmbH, 52425 Jülich, Germany.

${ }^{\S}$ Current address: Bioaster Technology Research Institute - Bioassays, Microsystems \& Optics Engineering Unit, 40 Avenue

10 Tony Garnier, 69007 Lyon, France

*Correspondence to: Albert A. Ruth (a.ruth@ucc.ie)

† Rolf Häseler - passed away on 25 July 2017.

出 Theodor Brauers - passed away on 21 February 2014.

15

Abstract. An instrument based on $20 \mathrm{~m}$ open-path incoherent broadband cavity-enhanced absorption spectroscopy (IBBCEAS) was established at the Jülich SAPHIR chamber in Spring 2011. The setup was optimized for the detection of $\mathrm{HONO}$ and $\mathrm{NO}_{2}$ in the near UV region 352-386 nm, utilizing a bright hot-spot Xe-arc lamp and a UV-enhanced CCD detector. A $2 \sigma$ detection limit of 26 pptv for $\mathrm{HONO}$ and 76 pptv for $\mathrm{NO}_{2}$ was achieved for an integration time of 1 min. Methacrolein

20 has also been detected at mixing ratios below 5 ppbv. The IBBCEAS instrument's performance for $\mathrm{HONO}$ and $\mathrm{NO}_{2}$ detection was compared to that of extractive wet techniques, long-path absorption photometry (LOPAP) and chemiluminescence spectrometry (CLS) $\mathrm{NO}_{\mathrm{X}}$ detection, respectively.

\section{Introduction}

Photolysis of nitrous acid $(\mathrm{HONO}+\mathrm{h} v(\lambda<400 \mathrm{~nm}) \rightarrow \mathrm{OH}+\mathrm{NO})$ leads to the formation of the most important daytime oxidant in the atmosphere, the hydroxyl radical $(\mathrm{OH})$. Thus HONO indirectly affects the oxidative potential of the troposphere and strongly influences degradation mechanisms of a vast variety of natural and urban pollutants. The mechanisms of HONO formation in the troposphere are still not fully understood (Calvert et al. 1994, Finlayson-Pitts et al. 2003, Ramazan et al. 2004, Liu et al. 2019). Many atmospheric studies revealed elevated HONO mixing ratios during daytime under specific conditions that cannot be fully explained (Staffelbach et al. 1997, Zhou et al. 2002a, Zhou et al. 2003, Kleffmann et al. 2003, Vogel et al.

30 2003, Kleffmann et al. 2005, Acker et al. 2006, Spataro and Ianniello, 2014). Although there appears to be general agreement that heterogeneous $\mathrm{NO}_{2}$ chemistry is one of the most important sources of HONO (Harrison et al. 1994, Reisinger 2000), 
https://doi.org/10.5194/amt-2021-291

Preprint. Discussion started: 22 November 2021

(c) Author(s) 2021. CC BY 4.0 License.
Atmospheric

Measurement

Techniques

Discussions

modelled HONO mixing ratios are often significantly below observed values (Vogel et al. 2003, Lammel and Cape 1996). However, other sources have also been suggested (Stemmler et al. 2006, Li et al. 2012, 2014). Since the photochemistry of HONO is closely connected to that of $\mathrm{NO}_{2}$ (Johnston et al. 1974, Aumont et al. 2003, Bröske et al. 2003, Ramazan et al.

35 2004), the in situ measurement of time-dependent $\mathrm{HONO}$ and $\mathrm{NO}_{2}$ mixing ratios by monitoring both species simultaneously is particularly interesting to elucidate the natural formation processes of HONO (Kleffmann 2003). One reason for the indeterminate formation and atmospheric role of $\mathrm{HONO}$ is the challenge to accurately and reliably quantify this species.

A direct spectroscopic way to detect HONO is through its electronic absorption in the near UV between 320 and $390 \mathrm{~nm}$ (Stutz et al. 2000), or through its IR active vibrational modes (Barney et al. 2000), e.g. in the Q-branches of trans-HONO at $1263 \mathrm{~cm}^{-}$

$40{ }^{1}\left(v_{3}\right)$ or $790 \mathrm{~cm}^{-1}\left(v_{4}\right)$. The cross-sections in both cases are approximately between $\sim 2$ and $6 \times 10^{-19} \mathrm{~cm}^{2} / \mathrm{molecule}$. The UV region has been extensively exploited in differential optical absorption spectroscopy (DOAS) (Febo et al. 1996, Alicke et al. 2003, Stutz et al. 2010), but more recently also using cavity enhanced methodologies (Wang and Zhang 2000, Djehiche et al. 2011, Jain et al. 2011), especially incoherent broadband cavity enhanced absorption spectroscopy (IBBCEAS) (Gherman et al. 2008, Hoch et al. 2012, Wu et al. 2012, Donaldson et al. 2014, Scharko et al. 2014, Min et al. 2016, Nakashima and

45 Sadanaga 2017, Duan et al. 2018, Jordan and Osthoff 2020, and Yi et al. 2021). The mid-IR was targeted using Fourier transform (Hanst et al. 1982) and tuneable diode laser spectroscopy (TDLAS) (Schiller et al. 2001). Laser-induced fluorescence (LIF) can also be used for sensitive HONO detection, but only through the emission of $\mathrm{OH}$ radicals that are formed after HONO photolysis (Rodgers and Davis 1989, Liao et al. 2006, Bottorff et al. 2021).

Most non-spectroscopic (indirect) detection methods are chemical in nature. Typical approaches comprise dry (Ferm and

50 Sjödin 1985), and wetted effluent diffusion (Simon and Dasgupta 1995, Acker et al. 2006), or rotated (Oms et al. 1996, Spindler et al. 2003) denuders, HPLC/fluorescence methods (Huang et al. 2002, Takenaka et al. 2004, Beine et al. 2005), or long path absorption photometry (LOPAP) (Heland et al. 2001, Kleffmann et al. 2002). The corresponding instrumentation is generally more sensitive than spectroscopic methods, but at the same time also more susceptible to chemical interferences that can affect the selectivity and quantification of HONO (Beine et al. 2005, Kleffmann et al. 2006). In most of the chemical methods HONO 55 is sampled on humid or liquid surfaces where heterogeneous chemistry can affect HONO mixing ratios in the presence of specific interfering chemicals (Ferm et al. 1985, Spindler et al. 2003, Zhou et al. 2003, Gherman et al. 2008). Moreover, photolytic or heterogeneous formation of HONO in sampling lines are known to cause unreliable results in in situ measurements (Zhou et al. 2002a, 2002b, Rohrer et al. 2005). Therefore for studies aiming at HONO detection it is essential to compare the performance of instruments that use genuinely different approaches (Kleffmann 2007). E.g. validation studies

60 of denuder based approaches against DOAS measurements illustrated that significant discrepancies exist for daylight/illuminated conditions (Kleffmann 2007). DOAS was also compared with the LOPAP approach and several reasons for systematic differences in the acquired data were identified (Kleffmann et al. 2006). 
A long open-path broad-band cavity enhanced absorption instrument was set up at the SAPHIR ${ }^{1}$ chamber at Forschungszentrum Jülich (Germany) in 2011, utilizing an incoherent short-arc Xe lamp as a light source (cf. Fiedler et al.

65 2003, Varma et al. 2009). Results of measurements to characterize its performance in the near UV through the in situ detection of $\mathrm{HONO}$ and $\mathrm{NO}_{2}$, as well as methacrolein (MACR) are presented here. Similar to the recent work by Yi et al. 2021 our objectives in 2011 were (i) to assess the instrument's performance concerning HONO detection and validate it with the LOPAP system available at SAPHIR, and (ii) to compare its performance concerning $\mathrm{NO}_{2}$ detection with the local SAPHIR chemiluminescence spectrometry (CLS) $\mathrm{NO}_{\mathrm{X}}$ detector.

Section 2 outlines details on the experimental setup at SAPHIR in Jülich. Section 3 shows measurements of HONO, $\mathrm{NO}_{2}$ and MACR mixing ratio using the IBBCEAS instrument. The data are respectively compared with results from different instruments at SAPHIR: (a) a LOPAP system (HONO), (b) a standardized chemiluminescence detector $\left(\mathrm{NO}_{2}\right)$, and (c) a protontransfer reaction mass spectrometer (PTRMS) (MACR). Correlation plots between individual measurements will be discussed for three measurement days in Summer and Autumn 2011. The experiments presented here supplement a campaign on the

75 "Formal Intercomparison of Observations of Nitrous Acid" (FIONA) (Rodenas et al. 2013), where instruments for the detection of HONO were compared at the EUPHORE simulation chambers in Valencia (Spain) in May 2009.

\section{Experiment}

IBBCEAS has been used for the detection of a variety of target species in different wavelength regions in the laboratory (Langridge et al. 2006, Washenfelder et al. 2008, Dixneuf et al. 2009, Thalman and Volkamer 2010, Wu et al. 2009, Nakashima 80 and Sadanaga 2017, Duan et al. 2018) and in outdoor environments (Bitter et al. 2005, Saiz-Lopez et al. 2006, Leigh et al. 2010, Wu et al. 2012). The high sensitivity and spatial resolution of open-path IBBCEAS make this approach particularly attractive for applications in atmospheric simulation chambers (Varma et al. 2009, Fuchs et al. 2010, Chen et al. 2011, AshuAyem et al. 2012, Hoch et al. 2012, Dorn et al. 2013, Rodenas et al. 2013). Thus an open-path IBBCEAS instrument was developed at the Jülich SAPHIR chamber, a facility designed for the simulation of tropospheric scenarios at realistically low mixing ratios of relevant trace species. The SAPHIR chamber is an ideal testbed for open-path IBBCEAS due to the available comprehensive suite of standard detection methods that can be used to assess and validate the data taken with IBBCEAS. For the experiments presented here the IBBCEAS instrument was optimized for the near-UV detection of HONO (352-386 nm), whose identification was based on three prominent absorption bands peaking at $\approx 354, \approx 368$ and $\approx 384 \mathrm{~nm}$ (Stutz et al. 2000). The spectral region covered also enabled the simultaneous detection of $\mathrm{NO}_{2}$ and methacrolein.

90 The experimental design of the IBBCEAS instrument was similar to the one described in Refs. (Varma et al. 2009, Dorn et al. 2013, Varma et al. 2013). It comprised a transmitter and a receiver unit, each housing one of the cavity mirrors. A sketch of the optical setup and details on experimental components are shown in Figures S1-S3 in the supplementary material. The

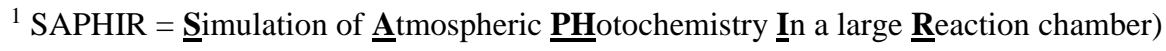


transmitter unit was mounted on a concrete platform at the north end of SAPHIR (facing south). The receiver unit was located at the south end of SAPHIR (facing north), in order to minimize exposure of the detector to potential daytime stray light. The dielectric mirrors $(r=-21 \mathrm{~m}, R \sim 0.999$, diameter $=40 \mathrm{~mm}$, Layertec $\mathrm{GmbH})$ inside the mechanically stable units formed an optical cavity with a mirror separation of $\sim 20.4 \mathrm{~m}$. Each unit was temperature stabilized with an air-to-air thermoelectric assembly (Laird Technologies). Vertical metal plates with optical ports (Figure S3) were rigidly mounted to the concrete support and formed the interface between the instrument's units and the chamber. Pipes connected to the two units extended into the SAPHIR chamber through the optical ports. Due to the use of the vertical plates (sealed by o-rings) the mechanical stress of the chamber's teflon wall was not imposed directly on the two optical units, which essentially decoupled the instrument from the chamber wall and improved its long-term stability. Each unit had two ports: one pipe with $50 \mathrm{~mm}$ diameter and another one with $25 \mathrm{~mm}$. In each unit the wider pipe was aligned along the optical axis of the cavity reducing the contribution of stray light to the measured signal in the receiver unit. The pipes were sealed with a high reflectivity mirror at one end and purged with zero air at a flow rate of $1.7 \mathrm{dm}^{3} \mathrm{~min}^{-1}$ during measurements to protect the mirror. The narrower pipe, which was sealed off during normal use of the instrument, was only used as a port for a green alignment laser (see Figure S1). The main light source was a short-arc Xe lamp running in "hot-spot" mode. In this mode, a small plasma spot ( 150 $\mu$ m diameter $)$ with a spectral radiance of $18 \mathrm{~W} \mathrm{~cm}^{-2} \mathrm{sr}^{-1} \mathrm{~nm}^{-1}$ at $400 \mathrm{~nm}$ was formed close to the cathode surface, improving the imaging properties of the discharge in comparison to conventional diffuse arcs. Small random jumps of the arc position, however, required an active stabilization of the beam direction by means of a quadrant detector. When the spot "jumped" to a specific quadrant an actively controlled piezo-driven Al-mirror was used to minimise the resulting beam deviation from the optical axis of the CEAS instrument. A telescope imaged the incoherent light into the optically stable cavity whose mirrors were aligned by two remote-controlled high resolution positioning motors per mirror. The light transmitted by the cavity was collected by a UVenhanced Al-mirror and focused onto the aperture of a circular-to-rectangular fiber bundle which guided the light onto the entrance slit $(25 \mu \mathrm{m})$ of a (Shamrock 303i) spectrograph ( $\mathrm{f}=303 \mathrm{~mm}, \mathrm{~F} / 4)$ supplied with a 1200 grooves/mm holographic

115 grating. The light transmitted by the spectrograph was imaged onto a CCD detector cooled to $-65^{\circ} \mathrm{C}$. Light outside the high reflectivity range of the cavity mirrors was optically filtered by means of a band-pass filter to avoid excessive scattering into the spectrometer and the potential saturation of the detector. The wavelength range from 352 to $386 \mathrm{~nm}$ was covered with a spectral resolution of $\sim 0.24 \mathrm{~nm}$. A sample of transmission spectra can be found in the supplementary material (Figure S4).

\subsection{Measurement Procedure}

120 After overnight flushing of the chamber with dry synthetic air (also referred to as "zero air" in this publication) the cavity transmission, $I_{0}(\lambda)$, was measured every morning in the dark chamber before experiments commenced. Typically 300 cavity transmission spectra with an individual acquisition time of $200 \mathrm{~ms}$ were accumulated during experiments, yielding a time resolution of 1 min per measured spectrum $I(\lambda)$. The extinction coefficient $\varepsilon(\lambda)\left[\mathrm{cm}^{-1}\right]$ was calculated according to (the left part of) Eq. (1): 


$$
\varepsilon(\lambda)=\frac{1-R_{\mathrm{eff}}(\lambda)}{d}\left(\frac{I_{0}(\lambda)}{I(\lambda)}-1\right)=a_{0}+a_{1} \lambda+a_{2} \lambda^{2}+a_{3} \lambda^{3}+a_{4} \lambda^{4}+\sum_{\mathrm{i}=1}^{N} n_{\mathrm{i}} \sigma_{\mathrm{i}}(\lambda)
$$

where $R_{\text {eff }}$ represents the wavelength dependent effective reflectivity of the cavity mirrors and $d=19.57 \mathrm{~m}$ the interaction path length per pass in the cavity ( $d$ equals the mirror separation minus the length corresponding to the mirror purge volume, see supplementary material, Figure S1). ( $\left.1-R_{\text {eff }}\right)$ comprises all effective optical losses of the cavity when filled with zero air after purging the chamber overnight; i.e. mirror reflectivity losses, Rayleigh (and potentially) Mie scattering losses, diffraction losses. The spatial average of the number density $n_{\mathrm{i}}\left[\right.$ molecule $\mathrm{cm}^{-3}$ ] of the absorbing species i (= $\mathrm{HONO}, \mathrm{NO}_{2}$ and MACR) was retrieved by fitting the function on the right hand side in Eq. (1) to the measured extinction coefficient. $\sigma_{\mathrm{i}}$ [ $\mathrm{cm}^{2}$ molecule ${ }^{1}$ ] represent the absorption cross-sections of species i. The cross-sections for HONO (Stutz et al. 2000), $\mathrm{NO}_{2}$ (Mérienne et al. 1995) and MACR (Meller et al. 1990) were converted to the spectral resolution of the spectrometer using home-made Gaussian convolution software written in Fortran. The five fit parameters $a_{\mathrm{j}}(\mathrm{j}=0 \ldots 4) \mathrm{in}$ Eq. (1) belong to a fourth-order polynomial, accounting for unspecified additional losses, such as background featureless absorption, or Rayleigh and Mie scattering that may become relevant over time. The fitting procedure was based on least squares minimization using a singular value decomposition (SVD) procedure (Press et al. 1986, Varma et al. 2009) in order to eliminate biases of the fit due to parameter correlations. During a first test run of the SVD approach the wavelength of all cross-section reference spectra were individually shifted to further minimize the least square sum, and the optimized wavelengths were subsequently used in SVD analyses. For all reference spectra the typical shift was $\approx 0.10 \pm 0.05 \mathrm{~nm}$ and thus within the spectral resolution of the measurement. The absolute wavelength (e.g. used in Fig. 4) was calibrated with a low-pressure neon pen ray lamp. Reflectivity calibration issues will be discussed in the section 4.

\section{$145 \quad 2.2$ The LOPAP Instrument}

The LOPAP instrument used in this study has been described in detail by Häseler et al. 2009 and Li et al. 2014 in the context of several campaigns on airborne detection of HONO aboard a Zeppelin airship. Air is extracted through two sampling coils in series where HONO is stripped into the liquid phase. In both coils the air is exposed to equal flows of a solution (0.06 M sulphanilamide in $1 \mathrm{M} \mathrm{HCl}$ solution) in which $\mathrm{HONO}$ almost instantaneously reacts to forms a diazonium salt. While the first

150 coil removes HONO nearly quantitatively from the gas phase, only a fraction of other chemically interfering species are scrubbed. The second coil, however, samples that fraction of interfering species but only the remaining small amount of HONO. Using the difference of the signals derived from the two coils enables the influence of interfering species to be accounted for. The air is then separated from the liquid and the solutions are separately transferred into two mixing volumes, where a $0.8 \mathrm{mM}$ solution of $\mathrm{N}$-(1-naphthyl)ethylenediamine-dihydrochloride is added to generate an azodye. The azodye's 155 concentration is then determined by its optical absorption to determine HONO mixing ratios. The absorption cells for both 
channels consist of long length teflon tubing, acting as a liquid core waveguide (LCW). Visible light is sent through the tubing and detected by two small spectrometers.

The entire instrument was housed in a compact 19 " $r a c k\left(56(w) \times 60(d) \times 100(h) \mathrm{cm}^{3}\right)$ consisting of two "chemistry" units and one "electronics/detection unit". In order to avoid sampling artefacts in inlet lines the sampling unit was straightforwardly mounted inside SAHPIR about $0.3 \mathrm{~m}$ from the chamber wall at the north end and $1 \mathrm{~m}$ above the floor. The instrument's sampling frequency, time resolution, $3 \sigma$ detection limit, $1 \sigma$ precision, and accuracy of the instrument was $0.33 \mathrm{~Hz}, 4-5 \mathrm{~min}$, 10 pptv, 3 pptv, and $12 \%$, respectively. The measurement range of the instrument can in principle be varied by the length of the absorption tubes and by the use of different absorption wavelengths for the evaluation. In this study we used an optical path length of $2.9 \mathrm{~m}$.

\section{2.3 Chemiluminescence Spectrometry NOx Detector}

The $\mathrm{NO}_{\mathrm{x}}$ detector was located in a container underneath the chamber from where gas mixtures were sampled at a flow rate of $1 \mathrm{dm}^{3} \mathrm{~min}^{-1}$ through a teflon tube of ca. $6 \mathrm{~m}$ length (internal diameter $4 \mathrm{~mm}$ ) corresponding to an approximate residence time of $1 \mathrm{~s} . \mathrm{NO}_{2}$ was converted to NO by a pulsed LED photolytic converter at $395 \pm 8 \mathrm{~nm}$ (Droplet Measurement Technologies, BLC) in a volume of $17 \mathrm{ml}$ with a conversion efficiency of approximately 50\%. The LED in the converter was consecutively switched on and off to alternately determine $\mathrm{NO}$ and $\mathrm{NO}_{\mathrm{x}}$ concentrations. $\mathrm{NO}$ was detected by a customized CLS detector (Eco Physics TR 780 (Rohrer and Brüning 1992, Fuchs et al. 2010). $\mathrm{NO}_{2}$ mixing ratios were calculated using an interpolated value between two subsequent $\mathrm{NO}_{\mathrm{X}}$ measurements at a time when $\mathrm{NO}$ mixing ratio were measured. The instrument was calibrated using NO standard gas mixtures ( 2 ppmv $\mathrm{NO}$ in $\mathrm{N}_{2}$, BOC-Linde) and gas phase titration for $\mathrm{NO}_{2}$.

The fact that besides $\mathrm{NO}_{2}$ also $\mathrm{HONO}$ is photolysed at $395 \mathrm{~nm}$ to yield $\mathrm{NO}$ was accounted for by determining the corresponding

175 NO yield from HONO numerically from the spectrum of the LEDs. The HONO photolysis contribution to NO is less than $5 \%$ compared to that of $\mathrm{NO}_{2}$. The $1 \sigma$ accuracy of the chemiluminescence detector for $\mathrm{NO}_{2}$ was determined to be $\pm 7 \%$, based on the uncertainty of $\pm 5 \%$ of the $\mathrm{NO}$ standard used for the calibration and a $\pm 5 \%$ uncertainty for the $\mathrm{NO}_{2}$ conversion efficiency. The known interference of $5 \%$ towards $\mathrm{HONO}$ is not corrected in the final dataset and not included in this accuracy estimate.

\subsection{Proton Transfer Reaction - Mass Spectrometry (PTRMS)}

180 PTRMS was utilized to monitor methacrolein in the presence of $\mathrm{HONO}$ and $\mathrm{NO}_{2}$. Generally the PTRMS technique relies on soft chemical ionization to detect gaseous trace components. The target species are converted to product ions through the transfer of a proton from the reagent ion, $\mathrm{H}_{3} \mathrm{O}^{+}$. The trace gases $(\mathrm{X})$ are identified through the mass of the product ions usually being the protonated molecular mass $\left(\mathrm{XH}^{+}\right): \mathrm{H}_{3} \mathrm{O}^{+}+\mathrm{X} \rightarrow \mathrm{XH}^{+}+\mathrm{H}_{2} \mathrm{O}$. The PTRMS instruments applied here was a quadrupole mass spectrometer system (PTR-Quad-MSThe system features a switchable reagent ion source with $\mathrm{H}_{3} \mathrm{O}^{+}, \mathrm{NO}^{+}$and $\mathrm{O}_{2}{ }^{+}$as

185 precursor ions for the measurement and identification of a number of trace gases. Details on the PTRMS instrument were published earlier by Wisthaler et al. 2008. 


\section{Results}

Measurements of time-dependent mixing ratios of $\mathrm{HONO}, \mathrm{NO}_{2}$ and MACR using open-path IBBCEAS were taken during Summer and Autumn 2011, and compared with those utilizing long-path absorption photometry (LOPAP), chemiluminescence spectrometry (CLS) and proton transfer reaction mass spectrometry (PTRMS), respectively. The performance intercomparison study is exemplified on basis of measurements on the $11^{\text {th }}$ of July and on the $5^{\text {th }} \& 6^{\text {th }}$ of October 2011 , when different photochemical scenarios were simulated. The measurements in July were carried out as part of a Jülich internal photochemistry campaign $\left(6^{\text {th }}\right.$ June to $15^{\text {th }}$ July 2011), whose goal was to study the oxidation of isoprene $\left(\mathrm{H}_{2} \mathrm{C}=\mathrm{C}\left(\mathrm{CH}_{3}\right)-\mathrm{CH}_{2} \mathrm{CH}_{2}\right)$, methacrolein $\mathrm{CH}_{2}=\mathrm{C}\left(\mathrm{CH}_{3}\right)-\mathrm{CHO}$ or methyl vinyl ketone $\left(\mathrm{CH}_{3}-\mathrm{C}(\mathrm{O})-\mathrm{CH}=\mathrm{CH}_{2}\right)$ by hydroxyl $(\mathrm{OH})$ radicals at low $\mathrm{NO}_{\mathrm{X}}$ mixing ratios (Nehr et al. 2014, Fuchs et al. 2014). In contrast, the measurements in October were specifically designed for a comparison between LOPAP and IBBCEAS under well controlled low concentration conditions with no obvious potential chemical interferences disturbing the LOPAP instrument. Generally, after cleaning and humidifying the SAPHIR chamber HONO formation by unknown photo-induced reactions on the Teflon chamber walls and degradation was studied in experiments always including light-induced and dark reactions of HONO formation or destruction - the experimental protocols concerning changes in chamber conditions are given in the figure captions. The results obtained on the three days will be outlined in chronological order. The performance of the open-path IBBCEAS instrument will subsequently be discussed in the context of the different measurement condition and atmospheric scenarios together with that of the Jülich LOPAP instrument.

Figure 1

\subsection{Measurements on 11 July 2011}

205 Figure 1 (left panels) summarizes the time-dependent measurements of mixing ratios of $\mathrm{HONO}, \mathrm{NO}_{2}$ and MACR as determined by IBBCEAS (black symbols), LOPAP (red), CLS (blue) and PTRMS (green). The same color code is also used in Figures 2, 3 and 5. The vertical arrow in Figure 1 indicates the times when the cavity transmission through the clean chamber, $I_{0}(\lambda)$, was measured for ca. $10 \mathrm{~min} .11 \mathrm{July}$ is the only day for which the build-up of HONO was monitored during daylight conditions. The HONO mixing ratio increased after humidification of the bright chamber (for $48 \mathrm{~min}$ ) and decreased subsequently when $\mathrm{O}_{3}$ ( 40 ppbv) was introduced. At 9:15 hrs there is a marked but unexplained change in the data of HONO mixing ratios as measured by IBBCEAS in comparison to LOPAP. The increase in the noise of the IBBCEAS data occurred ca. 15 minutes before the addition of $\mathrm{CO}$ to the chamber at 9:30 hrs, which is neither expected to influence the HONO chemistry nor the data retrieval, even at high $\mathrm{CO}(\sim 750 \mathrm{pbbv})$ concentrations (see Figure 1). Presently there is no obvious explanation for this behavior in the IBBCEAS measurement. Likewise the return to dark conditions at 15:33 hrs led initially to an unexpected increase of

215 the HONO mixing ratio as recorded by the LOPAP instrument, but it was also observed by the IBBCEAS measurement. This observation was also made in other campaigns and will be briefly discussed in section 4.2. $\mathrm{NO}_{2}$ mixing ratios, as measured by CLS, increased gradually during humidification of the bright chamber and increased sharply when $\mathrm{O}_{3}$ was introduced, followed by a more gradual increase until MACR was added to the mixture at 11:51 hrs. The jump of the $\mathrm{NO}_{2}$ mixing ratio at 07:30 
shows the effect when $\mathrm{O}_{3}$ was added actively to the chamber. Almost all $\mathrm{NO}$ was oxidised to $\mathrm{NO}_{2}$ at that time. Both CLD and

CEAS show this effect. The observed temporary decrease of the $\mathrm{NO}_{2}$ concentration after the addition of MACR can be explained by a reaction sequence following the formation of $\mathrm{OH}$ from HONO: The primary oxidation step of the reaction of $\mathrm{OH}$ with MACR forms the peroxy methacryloyl radical $\left(\mathrm{CH}_{2}=\mathrm{C}\left(\mathrm{CH}_{3}\right)-\mathrm{C}(\mathrm{O}) \mathrm{OO}\right)$, part of which further reacts with $\mathrm{NO}_{2}$ to form MPAN (peroxy methacryloyl nitrate, $\left.\mathrm{CH}_{2}=\mathrm{C}\left(\mathrm{CH}_{3}\right)-\mathrm{C}(\mathrm{O}) \mathrm{OONO}_{2}\right)$. MPAN is thermally unstable with a small thermal decomposition rate of $\sim 4.6 \times 10^{-4} \mathrm{~s}^{-1}$ at $25^{\circ} \mathrm{C}$ (Roberts and Bertman 1992). Thus a thermal equilibrium is established from which $\mathrm{NO}_{2}$ is reformed after the initial MACR has been consumed (Fuchs et al. 2014).

Concentrations of $\mathrm{NO}_{2}$ and MACR both appeared to stagnate when the roof was closed due to the absence of light-driven photo-chemistry. Finally the purging of the chamber with synthetic air removed all trace gases from the chamber.

The experiments in October were designed to enable accurate mirror reflectivity calibration and intercomparison of LOPAP and IBBCEAS under unperturbed condition at sub-ppbv mixing ratios of HONO. The measurements demonstrate that the long-cavity IBBCEAS instrument at SAPHIR is capable of detecting HONO pptv levels without difficulty (Figures 2 and 3).

\subsection{Measurements on 5 October 2011}

After overnight flushing in the morning of 5 October, $\mathrm{NO}_{2}$ was added to the chamber in steps of 250 pptv (at 6:30 hrs and 6:50 hrs), $500 \mathrm{pptv}$ (at 7:10 and 7:30), and $1 \mathrm{ppbv}$ (at 7:50 hrs and 8:10 hrs). After subsequent humidification for $44 \mathrm{~min}$ (starting at 8:41 hrs) and the exposure to daylight at 9:27 hrs, HONO was formed at levels of up to 400 pptv. Finally, after closing the chamber roof (14:23 hrs), HONO was removed by flushing with zero air (starting at 15:31 hrs). The HONO data from the IBBCEAS and LOPAP setups, and the $\mathrm{NO}_{2}$ data from the IBBCEAS and CLS instruments showed outstanding agreement on that day (Fig. 2).

Figure 2

\subsection{Measurements on 6 October 2011}

240 It is known that the photo-enhanced formation of HONO in the SAPHIR chamber can be described by an empirical function depending on relative humidity, solar irradiation and temperature (Rohrer et al. 2005). Minimal HONO production was thus achieved by only humidifying the chamber for 42 min after overnight flushing with zero air. At 12:18 hrs the chamber was exposed to daylight leading to the gradual formation based on vestiges of $\mathrm{NO}_{\mathrm{X}}$ on the chamber wall. The variation of temperature was limited to the natural variability. After a gradual increase the HONO mixing ratios leveled off at ca. $250 \mathrm{pptv}$

245 before the chamber was eventually closed at 16:24 hrs. The correlation between the data obtained with IBBCEAS and LOPAP is rather satisfactory at these low levels. For $\mathrm{NO}_{2}$ there appears to be a slight offset between data from the IBBCEAS and CLS instruments with good overall agreement.

Figure 3 


\section{Discussion of Instruments' Performances}

\subsection{IBBCEAS Instrument}

The main experimental uncertainties determining the quality of the IBBCEAS data reported here are systematic; they are: (a) the stability of the light source, (b) the in situ calibration of the mirror reflectivity, (c) the data analysis and concentration retrieval approach, and (d) the unspecified mechanical instabilities of the setup such as potential thermal drifts or deficiencies of the opto-mechanical components (Ruth et al. 2014). The latter become more critical with increasing cavity length since small changes in the optical alignment have a more severe influence on the instrument's performance; see Varma et al. 2009.

\subsubsection{Lamp Stability}

Short-term intensity fluctuations are due to random spatial variations of the hot spot plasma arc (small arc jumps), whose effects on the optical alignment were minimised by an active quadrant detector control unit (Varma et al. 2009). As long as intensity fluctuations of the lamp do not show any spectral dependence in the wavelength range of interest, the resulting baseline changes can in principle be accounted for in the fit of eq (1) to the measured data. If the fluctuations are however accompanied by random spectral variation, the retrieval by SVD becomes increasingly difficult. Spatial jumps that were at the compensation limit of the quadrant detector were also noted during experiments leading to uncertainties in the baselines. One of these events may have occurred e.g. on 11 July at $~ 9: 30 \mathrm{hrs}$. Difficulties in the mixing ratio retrieval due to lamp instabilities occurred sporadically during the measurements in the Summer, but became more frequent and for longer time periods after continued use of the lamp in the Autumn. For instance the measurement on 6 Oct (Figure 3) was affected by lamp stability issues, which is a sign of electrode aging and the main cause for the hot spot plasma arc to wander into a domain where the stabilization system is unable to fully compensate for the spatial displacement.

An unexplained change in performance started approximately $20 \mathrm{~min}$ before the addition of $750 \mathrm{ppbv}$ of CO on 11 July at ca. 9:10 hrs (Figure 1). At that time the quality of the IBBCEAS data started to worsen, while the LOPAP performance remained largely unaffected (see Figure 1). A small increase in HONO mixing ratios was subsequently observed in comparison to the LOPAP and the noise of the IBBCEAS data was increased by roughly a factor of $\sim 2$. There are no obvious reasons for this observed behavior from a (photo)chemical point of view, since at the time the gas mixture was not altered. In open path cavity setups similar behavior can in principle be caused through increased scattering due to particle formation (Varma et al. 2009), but measurements of the particle number concentration showed no significant change on this occasion. Therefore one conceivable explanation may be that the hot spot arc in the Xe lamp may have moved to a steady location on the electrode where the control unit was at its performance limit to keep the arc steady. As the quadrant detector correction signal was not recorded, this is merely a tentative explanation of the sudden change of performance. Although there was an addition of $\mathrm{CO}$ a short time later it is not plausible that potential impurities in the $\mathrm{CO}$ (purity >99.9\%) gas (or chemical reactions of same) might be the cause for this observation. LED-based IBBCEAS is generally less prone to sudden changes (Gherman et al. 2008) due to the higher stability of the light source, although slow drifts are still possible (Fouqueau et al. 2020). 


\subsubsection{Mirror Reflectivity and Calibration Aspects}

Retrieval of accurate mixing ratios by IBBCEAS requires the effective mirror reflectivity $R_{\text {eff }}$ to be known accurately as a function of wavelength. Calibration measurements were performed a few times over the course of the measurements presented here by introducing a known amount of $\mathrm{NO}_{2}$ into the dry SAPHIR chamber shortly after the cavity transmission of the clean and dry cavity, $I_{0}(\lambda)$, had been recorded. The effective reflectivity was retrieved with eq (1) using the known cross-section of $\mathrm{NO}_{2}$ and the mixing ratio from the CLS NO $\mathrm{X}_{\mathrm{X}}$ monitor (e.g. using the measurements on $5^{\text {th }}$ Oct 2011 where $R_{\text {eff }}=0.9978$ at 352 $\mathrm{nm}$ and $R_{\text {eff }}=0.9986$ at $386 \mathrm{~nm}$, see supplementary Figure S5). The lower limit of the absolute uncertainty $(\sim 11 \%)$ is based on the accuracy of the $\mathrm{NO}_{2}$ cross-section (8\%) and that of the $\mathrm{NO}_{\mathrm{X}}$ measurement $(7 \%)$.

The initial calibration measurement of $R_{\text {eff }}$ was also used to determine the loss, $L_{\mathrm{LLO}}(\lambda)$, of an anti-reflection coated optic (referred to as "low loss optic", LLO), which was in turn used on a daily basis (in the morning) to determine the reflectivity in the clean chamber instead of using $\mathrm{NO}_{2}$ as calibration gas (see also supplementary Figures S4 and S6):

$$
R_{\mathrm{eff}}(\lambda)=1-\left(\frac{I_{\mathrm{LLO}}}{I_{0}-I_{\mathrm{LLO}}} L_{\mathrm{LLO}}(\lambda)\right)
$$

In the transmitter unit the LLO $\left(R_{\mathrm{LLO}}(375 \mathrm{~nm})<0.001\right.$, diameter $40 \mathrm{~mm}$, parallelism 30 ") was moved into and out of the cavity parallel to the mirror by means of an accurate translational stage with high reproducibility. Care was taken in designing the air-tight LLO compartment (Figure S1) where the optic was "parked" when not needed. The LLO was furthermore flushed with clean dry air while in the cavity to avoid (minimize) potential changes of its optical loss. When the LLO is used over the course of a simulation experiment, i.e. in a chamber with arbitrary gas mixture, the LLO measurements yield effective reflectivities that comprise extinction losses in the chamber at this particular time. Although only the $R_{\text {eff }}$ measured each morning in the clean dry and dark chamber was used to retrieve the concentrations of the target species (eq (1)) for the entire day, repeated introductions of the LLO into the cavity over the course of the day was used for checking whether misalignments or potential drifts of the cavity had occurred.

\subsubsection{Data Evaluation}

In order to judge the quality of the data evaluation an example of an IBBCEAS extinction spectrum and the corresponding fit of eq (1) to the measured data are shown in Figure 4 (uppermost panel). The data for this example were chosen because on 11 July $2011 \mathrm{HONO}, \mathrm{NO}_{2}$ and MACR were simultaneously present in the chamber. The different panels in Figure 4 show the individual absorption contributions of the three species to the measured spectrum together with the polynomial background

310 determined in the fit analysis. The lowermost panel shows the fit residuals, $\Delta \varepsilon$, illustrating the appropriate use of the reference absorption spectra of the three target species in this measurement. 


\subsubsection{Detection Limits}

For individually measured spectra a minimum extinction coefficient of $9.3 \times 10^{-10} \mathrm{~cm}^{-1}$ was determined for an acquisition time of $1 \mathrm{~min}$ (assuming a 1:1 signal-to-noise ratio), which corresponds to $\varepsilon_{\min }=7.2 \times 10^{-9} \mathrm{~cm}^{-1} \mathrm{~Hz}^{-1 / 2}(1 \sigma)$. For a series of measurements (see supplementary Figure S7) this translates into a measured $3 \sigma$ limit of detection (LOD) of the IBBCEAS instrument for a 1 min acquisition time of $\sim 39$ pptv for $\mathrm{HONO}, \sim 114$ pptv for $\mathrm{NO}_{2}$, and ca. 510 pptv for MACR in the 352$386 \mathrm{~nm}$ wavelength range.

In comparison to the IBBCEAS instrument, the LOPAP instrument at SAPHIR featured a $3 \sigma$ LOD of 10 pptv of HONO in $1 \mathrm{~min}$. The LOD for $\mathrm{NO}_{2}$ by the standardised chemiluminescence technique at SAPHIR also compares favourably with a $3 \sigma$ LOD of 13.4 pptv of $\mathrm{NO}_{2}$ for a 1 min acquisition time with an overall accuracy of 7 \% (Rohrer and Brüning 1992, Fuchs et al. 2010) (the CLS detection limit for NO is $\approx 6.7 \mathrm{pptv}$ ). Mixing ratios of volatile organic compounds such as methacrolein can be only compared to data acquired with PTRMS, whose LOD for MACR is 8.5 pptv in 1 min (accuracy $8 \%$ ).

An overview of $(2 \sigma)$ detection limits for HONO of previously published IBBCEAS instruments was recently given by Jordan and Osthoff 2020. The $2 \sigma$ detection limit of $26 \mathrm{pptv}$ for HONO in $1 \mathrm{~min}$ presented here compares favourably to the IBBCEAS works by Gherman et al. 2008, Hoch et al. 2012, Wu et al. 2012, Donaldson et al. 2014, Scharko et al. 2014, Min et al. 2016, Nakashima and Sadanaga 2017, Duan et al. 2018, and Jordan and Osthoff 2020 - see Table 1 in the AMT article by Jordan and Osthoff 2020. It should be noted, however, that some of the quoted detection limits were established under field conditions, which bears challenges that are different from experiments with a large scale simulation chamber. The rather competitive detection limits of the current setup are a result of the substantial cavity length, despite the fact that the effective cavity mirror reflectivity in this work was lower than in all other instruments reported.

Figure 4

\subsection{LOPAP Instrument}

In a previous DOAS-LOPAP intercomparison (Kleffmann et al. 2006) the addition of ozone triggered issues concerning the use of proper reference data in the DOAS evaluation procedure at ppbv levels of HONO. This sort of difficulty was not observed with IBBCEAS at sub-ppbv mixing ratios of HONO.

However, when switching from illuminated to dark conditions the LOPAP instrument regularly showed an increase of HONO concentrations, while the IBBCEAS detector does not seem to follow this trend as strongly and reproducibly; see Figure 1 (11 July 2011) or Figure S8, for example. The systematically increasing HONO mixing ratios measured by the LOPAP instrument upon closing the roof and generating dark conditions was also observed on a few other days during the summer campaign, e.g. on 10 and 15 June (see supplementary Figure S8). The reason for this behavior is not fully understood yet. An effect of the presence of organic reaction products from the oxidation of mathacrolein that cause an interference with the LOPAP technique upon stopping photolytic processes can be ruled out, because the "effect" was also observed in experiments with a clean humidified chamber solely filled with high purity synthetic (zero) air. A possible explanation may be based on the changing 
homogeneous and heterogeneous production rates of $\mathrm{HONO}$ versus its destruction rates under bright and dark conditions. For containing precursor adsorbed at the Teflon walls or dissolved in the surface water layer on the Teflon film versus the photolytic destruction of HONO into OH and NO. In the dark (closed) humidified chamber HONO can still be produced, but predominantly through heterogeneous reactions with formation rates being at least a factor of $\sim 10$ smaller than under illuminated conditions (i.e. with the roof open). Even though closing the roof stops efficient HONO production it also eliminates the photolytical loss entirely, while HONO heterogeneous production within the aqueous phase on the chamber walls is still active (albeit its slowly decreasing efficiency). This can lead to changing the equlibrum such that the subsequent outgassing of HONO from the aqueous phase on the Teflon film can temporarily dominate the HONO production into the gas phase until the initially HONO-saturated aqueous phase also gets depleted leading to the eventual decrease in HONO mixing ratios (Karl, 2004). The inlet of the LOPAP instrument is much closer to the chamber wall $(\mathrm{ca} .30 \mathrm{~cm})$ in comparison to the region probed by IBBCEAS, which averages across the whole length of the chamber near its center. Thus the effect is more likely to be apparent in the LOPAP data than in the IBBCEAS data. This tentative explanation of the observed trend upon closing the roof of the chamber warrants further investigation.

\subsection{CLS and PTRMS Instruments}

The CLS and PTRMS data were used here as reference guideline for the measurements and not for scrutinizing the performance of the respective instruments. Nevertheless, some discrepancies between IBBCEAS, CLS and PTRMS were noted and are outlined here.

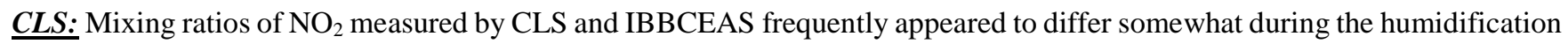
of the dark chamber. The CLS instrument appears to systematically record higher $\mathrm{NO}_{2}$ mixing ratios than IBBCEAS upon humidification of an initially clean chamber without the obvious presence of $\mathrm{NO}_{2}$. Examples of the observed behavior are shown in Figure 5 (see also Figure S8).

\section{Figure 5}

There are two possible scenarios that may explain these observations: (a) It could be an artefact in the chemiluminescence device, which may be due to a surface effect of the blue light converter (BLC). Switching from a dry to a humidified chamber leads to a severe change in the surface conditions of the BLC, which releases either NO or a substance that mimics an NO signal for some time until a new equilibrium has been reached. This type of behavior has occurred before in measurement campaigns at SAPHIR, where small temporary discrepancies between model calculations and measurement were observed. The nature of the potentially released substance is unclear. HONO would be more likely to stick to the walls rather than to be released unless heterogenous reactions are at play leading to the formation of NO. The effect is transient and vanishes after a

375 short time. The fact that rapidly changing water vapor concentrations can affect the instrumental background of CLS detectors and lead to a non-trivial memory effect that cannot be easily corrected retrospectively has also been reported recently in the 
literature (Nussbaumer et al. 2021). (b) A small contamination of the milli-Q water and differences in the sample quality used for humidification cannot be fully ruled out. Those contaminations have also been observed before. The increase in the $\mathrm{NO}_{2}$ signal upon humidification is supported by a significant increase in the NO signal ( 120 pptv) observed by CLS. However, on 10 June 2011 this increase seems to be over after ca. $15 \mathrm{~min}$ while the humidification is still ongoing. The reason why the IBBCEAS instrument does not detect the increase in $\mathrm{NO}_{2}$ if it is due to contamination is also unclear.

PTRMS: After introduction of MACR to the chamber on 11 July, initially higher mixing ratios were recorded by PTRMS rather than by IBBCEAS (between 11:50 hrs and ca. 15:30 hrs). The mixing ratios measured with the two instrument gradually approach very similar values over the said time period until they agree rather well when the roof of the chamber was closed. The reason for this behavior is not clear since no obvious interference in this period was obvious.

\subsection{Correlation of Data Obtained by Different Instrumental Methods}

For the combined data sets of the instrument intercomparisons an overall good agreement for both trend and absolute mixing ratios was observed between IBBCEAS and the established instruments at SAPHIR as illustrated in the correlation plots in Figures 6 and Table 1 (see also Figs. 1-3). The best agreement is observed on 5 Oct 2011 for both $\mathrm{HONO}$ and $\mathrm{NO}_{2}$, which may be attributed to the fact that the least amount of interfering species were present in the chamber at that time. $\mathrm{R}$ coefficients range from 0.930 to 0.994 for $\mathrm{HONO}$ and between 0.937 and 0.992 for $\mathrm{NO}_{2}$. An $\mathrm{R}$ coefficient of 0.962 is found for the single measurement of MACR.

\section{Conclusion}

In 2011 an incoherent broadband open-path cavity-enhanced absorption spectroscopy (IBBCEAS) instrument was established at the SAPHIR chamber in Jülich and optimized for the detection of $\mathrm{HONO}$ and $\mathrm{NO}_{2}$ in the near UV region (352-386 nm) using a bright hot-spot Xe-arc lamp and a UV-enhanced CCD detector. Based on an effective reflectivity of $0.9978<R_{\text {eff }}<$ 0.9986 and a 20 m open-path cavity a $2 \sigma$ detection limit of 26 pptv for $\mathrm{HONO}$ and 76 pptv for $\mathrm{NO}_{2}$ was achieved for an integration time of $1 \mathrm{~min}$. Methacrolein was also detected at mixing ratios below $5 \mathrm{ppbv}$. These are highly competitive detection limits in comparison to those reported in the recent literature. The IBBCEAS instrument's performance for $\mathrm{HONO}$ and $\mathrm{NO}_{2}$ detection was compared to that of long-path absorption photometry (LOPAP) and chemiluminescent $\mathrm{NO}_{\mathrm{X}}$ detection, with $\mathrm{R}$ coefficients range from 0.930 to 0.994 for $\mathrm{HONO}$, and between 0.937 and 0.992 for $\mathrm{NO}_{2}$, respectively. At low concentrations however, and especially upon humidification of the chamber, a small temporary water interference on $\mathrm{NO}_{2}$ mixing ratios were observed in CLS measurements which was not observed in the IBBCEAS data. 


\section{Acknowledgement}

SD gratefully acknowledges support through an INSPIRE post-doctoral fellowship by the Irish Research Council for Science Engineering and Technology which was cofounded by the Marie Curie actions, COFUND, under the Seventh European Framework Programme (FP7). We thank Andreas Wahner, Director of the Institute for Energy and Climate Research:

410 Troposphere (IEK-8) at the Research Center in Jülich (Germany), and the team running the SAPHIR chamber, especially Ralf Tillmann, for providing the PTRMS data for this publication. The extraordinary craftsmanship of the mechanical workshop at Jülich in the context of this project is also gratefully recognized.

\section{References}

Acker, K., Möller, D., Wieprecht, W., Meixner, F. X., Bohn, B., Gilge, S., Plass-Dülmer, C., and Berresheim, H.: Strong daytime production of $\mathrm{OH}$ from $\mathrm{HNO}_{2}$ at a rural mountain site, Geophys. Res. Lett., 33, L02809, doi: 10.1029/2005GL024643, 2006.

Alicke, B., Geyer, A., Hofzumahaus, A., Holland, F., Konrad, S., Patz, H. W., Schäfer, J., Stutz, J., Volz-Thomas, A., and Platt, U.: OH formation by HONO photolysis during the BERLIOZ experiment, J. Geophys. Res., 108, D4, doi: 10.1029/2001JD000579, 2003.

Ashu-Ayem, E. R., Nitschke, U., Monahan, C., Chen, J., Darby, S. B., Smith, P. D., O'Dowd, C. D., Stengel, D. B., and Venables, D. S.: Coastal iodine emissions. 1. Release of $\mathrm{I}_{2}$ by Laminaria Digitata in chamber experiments, Environ. Sci. Tech., 46, 10413-10421, doi: 10.1021/es204534v, 2012.

Aumont, B., Chervier, F., and Laval, S.: Contribution of $\mathrm{HONO}$ sources to the $\mathrm{NO}_{\mathrm{X}} / \mathrm{HO}_{\mathrm{X}} / \mathrm{O}_{3}$ chemistry in the polluted boundary layer, Atmos. Environ., 37, 487-498, doi: 10.1016/S1352-2310(02)00920-2, 2003.

Barney, W. S., Wingen, L. M., Lakin, M. J., Brauers, T., Stutz, J., and Finlayson-Pitts, B. J.: Infrared absorption cross-section measurements for nitrous acid (HONO) at room temperature, J. Phys. Chem. A, 104, 1692-1699, doi: 10.1021/jp010734d, 2000.

Beine, H. J., Amoroso, A., Esposito, G., Sparapani, R., Ianniello, A., Georgiadis, T., Nardino, M., Bonasoni, P., Cristofanelli, P., and Dominé, F.: Deposition of atmospheric nitrous acid on alkaline snow surfaces, Geophys. Res. Lett., 32, L10808, doi: 10.1029/2005GL022589, 2005.

Bitter, M., Ball, S. M., Povey, I. M., and Jones, R. L.: A broadband cavity ringdown spectrometer for in-situ measurements of atmospheric trace gases, Atmos. Chem. Phys., 5, 2547-2560, doi: 10.5194/acp-5-2547-2005, 2005.

Bottorff, B., Reidy, E., Mielke, L., Dusanter, S., and Stevens, P. S.: Development of a laser-photofragmentation laser-induced fluorescence instrument for the detection of nitrous acid and hydroxyl radicals in the atmosphere, Atmos. Meas. Tech., 14, 6039-6056, doi: 10.5194/amt-14-6039-2021, 2021. 
https://doi.org/10.5194/amt-2021-291

Preprint. Discussion started: 22 November 2021

(c) Author(s) 2021. CC BY 4.0 License.
Atmospheric

Measurement

Techniques

Discussions

Bröske, R., Kleffmann, J., and Wiesen, P.: Heterogeneous conversion of $\mathrm{NO}_{2}$ on secondary organic aerosol surfaces: A possible source of nitrous acid (HONO) in the atmosphere? Atmos. Chem. Phys., 3, 469-474, doi: 10.5194/acp-3-469-2003, 2003.

Calvert, J. G., Yarwood, G., and Dunker, A. M.: An evaluation of the mechanism of nitrous acid formation in the urban atmosphere, Res. Chem. Intermed., 20, 463-502, doi: 10.1163/156856794X00423, 1994.

Chen, J., Wenger, J. C., and Venables, D. S.: Near-ultraviolet absorption cross sections of nitrophenols and their potential influence on tropospheric oxidation capacity, J. Phys. Chem. A, 115, 12235-12242, 10.1021/jp206929r, 2011.

Dixneuf, S., Ruth, A. A., Vaughan, S., Varma, R. M., and Orphal, J.: The time dependence of molecular iodine emission from Laminaria digitata, Atmos. Chem. Phys., 9, 823-829, doi: 10.5194/acp-9-823-2009, 2009.

Djehiche, M., Tomas, A., Fittschen, C., and Coddeville, P.: First direct detection of HONO in the reaction of methylnitrite $\left(\mathrm{CH}_{3} \mathrm{ONO}\right)$ with $\mathrm{OH}$ radicals, Environ. Sci. Tech., 45, 608-614, doi: 10.1021/es103076e, 2011.

Donaldson, M. A., Berke, A. E., and Raff, J. D.: Uptake of gas phase nitrous acid onto boundary layer soil surfaces, Environ. Sci. Tech., 48, 375-383, doi: 10.1021/es404156a, 2014.

Dorn, H. P., Apodaca, R. L., Ball, S. M., Brauers, T., Brown, S. S., Crowley, J. N., Dubé, W. P., Fuchs, H., Häseler, R., Heitmann, U., Jones, R. L., Kiendler-Scharr, A., Labazan, I., Langridge, J. M., Meinen, J., Mentel, T. F., Platt, U., Pöhler, D., Rohrer, F., Ruth, A. A., Schlosser, E., Schuster, G., Shillings, A. J. L., Simpson, W. R., Thieser, J., Tillmann, R., Varma, R., Venables, D. S., and Wahner, A.: Intercomparison of $\mathrm{NO}_{3}$ radical detection instruments in the atmosphere simulation chamber SAPHIR, Atmos. Meas. Tech., 6, 1111-1140, doi: 10.5194/amt-6-1111-2013, 2013.

Duan, J., Qin, M., Ouyang, B., Fang, W., Li, X., Lu, K., Tang, K., Liang, S., Meng, F., Hu, Z., Xie, P., Liu, W., and Häseler, R.: Development of an incoherent broadband cavity-enhanced absorption spectrometer for in situ measurements of HONO and $\mathrm{NO}_{2}$, Atmos. Meas. Tech., 11, 4531-4543, doi: 10.5194/amt-11-4531-2018, 2018.

Febo, A., Perrino, C., and Allegrini, I.: Measurement of nitrous acid in Milan, Italy, by DOAS and diffusion denuders, Atmos. Environ., 30, 3599-3609, doi: 10.1016/1352-2310(96)00069-6, 1996.

Ferm, M., and Sjödin, A.: A sodium carbonate coated denuder for determination of nitrous acid in the atmosphere, Atmos. Environ., 19, 979-983, doi: 10.1016/0004-6981(85)90243-4, 1985.

Fiedler, S. E., Hese, A., and Ruth, A. A.: Incoherent broad-band cavity-enhanced absorption spectroscopy, Chem. Phys. Lett., 371, 284-294, doi: 10.1016/S0009-2614(03)00263-X, 2003.

Finlayson-Pitts, B. J., Wingen, L. M., Sumner, A. L., Syomin, D., and Ramazan, K. A.: The heterogeneous hydrolysis of $\mathrm{NO}_{2}$ in laboratory systems and in outdoor and indoor atmospheres: An integrated mechanism, Phys. Chem. Chem. Phys. 5, 223-242, doi: 10.1039/B208564J, 2003.

Fouqueau, A., Cirtog, M., Cazaunau, M., Pangui, E., Zapf, P., Siour, G., Landsheere, X., Méjean, G., Romanini, D., and Picquet-Varrault, B.: Implementation of an incoherent broadband cavity-enhanced absorption spectroscopy technique in an atmospheric simulation chamber for in situ $\mathrm{NO}_{3}$ monitoring: characterization and validation for kinetic studies, Atmos. Meas. Tech., 13, 6311-6323, doi: 10.5194/amt-13-6311-2020, 2020. 
Fuchs, H., Ball, S. M., Bohn, B., Brauers, T., Cohen, R. C., Dorn, H.-P., Dubé, W. P., Fry, J. L., Häseler, R., Heitmann, U., Jones, R. L., Kleffmann, J., Mentel, T. F., Müsgen, P., Rohrer, F., Rollins, A. W., Ruth, A. A., Kiendler-Scharr, A., Schlosser, E., Shillings, A. J. L., Tillmann, R., Varma, R. M., Venables, D. S., Villena Tapia, G., Wahner, A., Wegener, R., Wooldridge, P. J., and Brown, S. S.: Intercomparison of measurements of $\mathrm{NO}_{2}$ concentrations in the atmosphere simulation chamber SAPHIR during the NO3Comp campaign, Atmos. Meas. Tech., 3, 21-37, doi: 10.5194/amt-3-21$\underline{2010}, 2010$.

Fuchs, H., Acir, I. H., Bohn, B., Brauers, T., Dorn, H.-P., Häseler, R., Hofzumahaus, A., Holland, F., Kaminski, M., Li, X., Lu, K., Lutz, A., Nehr, S., Rohrer, F., Tillmann, R., Wegener, R., and Wahner, A.: OH regeneration from methacrolein oxidation investigated in the atmosphere simulation chamber SAPHIR, Atmos. Chem. Phys., 14, 7895-7908, doi: 10.5194/acp-14-7895-2014, 2014.

Gherman, T., Venables, D. S., Vaughan, S., Orphal, J., and Ruth, A. A.: Incoherent broadband cavity-enhanced absorption spectroscopy in the near-ultraviolet: Application to $\mathrm{HONO}$ and $\mathrm{NO}_{2}$, Environ. Sci. Tech., 42, 890-895, doi: $\underline{10.1021 / \mathrm{es} 0716913}, 2008$.

Häseler, R., Brauers, T., Holland, F., and Wahner, A.: Development and application of a new mobile LOPAP instrument for the measurement of HONO altitude profiles in the planetary boundary layer, Atmos. Meas. Tech. Discuss., 2, 20272054, doi: 10.5194/amtd-2-2027-2009, 2009.

Hanst, P. L., Wong, N. W., and Bragin, J.: A long-path infrared study of Los Angeles smog, Atmos. Environ., 16, 969-981, doi: 10.1016/0004-6981(82)90183-4, 1982.

Harrison, R. M., and Kitto, A. M. N.: Evidence for a surface source of atmospheric nitrous acid, Atmos. Environ., 28, 10891094, doi: 10.1016/1352-2310(94)90286-0, 1994.

Heland, J., Kleffmann, J., Kurtenbach, R., and Wiesen, P.: A new instrument to measure gaseous nitrous acid (HONO) in the atmosphere, Environ. Sci. Tech., 35, 3207-3212, doi: 10.1021/es000303t, 2001.

Hoch, D. J., Buxmann, J., Sihler, H., Pöhler, D., Zetzsch, C., and Platt, U.: A cavity-enhanced differential optical absorption spectroscopy instrument for measurement of BrO, $\mathrm{HCHO}, \mathrm{HONO}$ and $\mathrm{O}_{3}$, Atmos. Meas. Tech. Discuss., 5, 3079-3115, doi: 10.5194/amtd-5-3079-2012, 2012.

495 Huang, G., Zhou, X. L., Deng, G. H., Qiao, H. C., and Civerolo, K.: Measurements of atmospheric nitrous acid and nitric acid, Atmos. Environ., 36, 2225-2235, doi: 10.1016/S1352-2310(02)00170-X, 2002.

Jain, C., Morajkar, P., Schoemaecker, C., Viskolcz, B., and Fittschen, C.: Measurement of absolute absorption cross sections for nitrous acid (HONO) in the near-infrared region by the continuous wave cavity ring-down spectroscopy (cw-CRDS) technique coupled to laser photolysis, J. Phys. Chem. A, 115, 10720-10728, doi: 10.1021/jp203001y, 2011.

500 Johnston, H. S., and Graham, R.: Photochemistry of $\mathrm{NO}_{\mathrm{x}}$ and $\mathrm{HNO}_{\mathrm{x}}$ compounds, Can. J. Chem.-Rev. Can. Chim., 52, 14151423, doi: $\underline{10.1139 / \mathrm{v} 74-214}, 1974$. 
https://doi.org/10.5194/amt-2021-291

Preprint. Discussion started: 22 November 2021

(c) Author(s) 2021. CC BY 4.0 License.
Atmospheric

Measurement

Techniques

Discussions

Jordan, N., and Osthoff, H. D.: Quantification of nitrous acid (HONO) and nitrogen dioxide $\left(\mathrm{NO}_{2}\right)$ in ambient air by broadband cavity-enhanced absorption spectroscopy (IBBCEAS) between 361-388 nm, Atmos. Meas. Tech., 13, 273-285, doi: 10.5194/amt-13-273-2020, 2020.

Karl, M.: Modellierung atmosphärisch-chemischer Reaktionen in der Tageslicht-Atmosphären-Simulationskammer SAPHIR, Dissertation, Westfälische Wilhelms-Universität Münster, 2004.

Kleffmann, J., Heland, J., Kurtenbach, R., Lorzer, J., and Wiesen, P.: A new instrument (LOPAP) for the detection of nitrous acid (HONO), Environ. Sci. Pollut. Res., 4, 48-54, doi: 10.1021/es000303t, 2002.

Kleffmann, J., Kurtenbach, R., Lorzer, J., Wiesen, P., Kalthoff, N., Vogel, B., and Vogel, H.: Measured and simulated vertical profiles of nitrous acid - Part I: Field measurements, Atmos. Environ., 37, 2949-2955, doi: 10.1016/S13522310(03)00242-5, 2003.

Kleffmann, J., Gavriloaiei, T., Hofzumahaus, A., Holland, F., Koppmann, R., Rupp, L., Schlosser, E., Siese, M., and Wahner, A.: Daytime formation of nitrous acid: A major source of $\mathrm{OH}$ radicals in a forest, Geophys. Res. Lett. - Atmos. Sci., 32, L05818, doi: 10.1029/2005GL022524, 2005.

Kleffmann, J., Lörzer, J. C., Wiesen, P., Kern, C., Trick, S., Volkamer, R., Rodenas, M., and Wirtz, K.: Intercomparison of the DOAS and LOPAP techniques for the detection of nitrous acid (HONO), Atmos. Environ., 40, 3640-3652, doi: 10.1016/j.atmosenv.2006.03.027, 2006.

Kleffmann, J.: Daytime sources of nitrous acid (HONO) in the atmospheric boundary layer, Chem. Phys. Chem., 8, 11371144, doi: $\underline{10.1002 / \mathrm{cphc} .200700016,2007 .}$

Lammel, G., and Cape, J. N.: Nitrous acid and nitrite in the atmosphere, Chem. Soc. Rev., 25, 361-369, doi: 10.1039/CS9962500361, 1996.

Langridge, J. M., Ball, S. M., and Jones, R. L.: A compact broadband cavity enhanced absorption spectrometer for detection of atmospheric $\mathrm{NO}_{2}$ using light emitting diodes, Analyst, 131, 916-922, doi: 10.1039/B605636A, 2006.

Leigh, R. J., Ball, S. M., Whitehead, J., Leblanc, C., Shillings, A. J. L., Mahajan, A. S., Oetjen, H., Lee, J. D., Jones, C. E., Dorsey, J. R., Gallagher, M., Jones, R. L., Plane, J. M. C., Potin, P., and McFiggans, G.: Measurements and modelling of molecular iodine emissions, transport and photodestruction in the coastal region around Roscoff, Atmos. Chem. Phys., 10, 11823-11838, doi: 10.5194/acp-10-11823-2010, 2010.

Li, X., Brauers, T., Häseler, R., Bohn, B., Fuchs, H., Hofzumahaus, A., Holland, F., Lou, S., Lu, K. D., Rohrer, F., Hu, M., Zeng, L. M., Zhang, Y. H., Garland, R. M., Su, H., Nowak, A., Wiedensohler, A., Takegawa, N., Shao, M., and Wahner, A.: Exploring the atmospheric chemistry of nitrous acid (HONO) at a rural site in Southern China, Atmos. Chem. Phys., 12, 1497-1513, doi: 10.5194/acp-12-1497-2012, 2012.

Li, X., Rohrer, F., Hofzumahaus, A., Brauers, T., Häseler, R., Bohn, B., Broch, S., Fuchs, H., Gomm, S., Holland, F., Jäger, J., Kaiser, J., Keutsch, F. N., Lohse, I., Lu, K. D., Tillmann, R., Wegener, R., Wolfe, G. M., Mentel, T. F., KiendlerScharr, A., and Wahner, A.: Missing gas-phase source of HONO inferred from zeppelin measurements in the troposphere, Science, 344, 292-296, doi: 10.1126/science.1248999, 2014. 
https://doi.org/10.5194/amt-2021-291

Preprint. Discussion started: 22 November 2021

(c) Author(s) 2021. CC BY 4.0 License.
Atmospheric

Measurement

Techniques

Discussions

Liao, W., Hecobian, A., Mastromarino, J., and Tan, D.: Development of a photo-fragmentation/laser-induced fluorescence measurement of atmospheric nitrous acid, Atmos. Environ., 40, 17-26, doi: 10.1016/j.atmosenv.2005.07.001, 2006.

Liu, Y., Nie, W., Xu, Z., Wang, T., Wang, R., Li, Y., Wang, L., Chi, X., and Ding, A.: Contributions of different sources to nitrous acid (HONO) at the SORPES station in eastern China: results from one-year continuous observation, Atmos. Chem. Phys. Discuss., doi: 10.5194/acp-2019-219, (in review), 2019.

Meller, R., private communication to, Röth, E.-P., Ruhnke, R., Moortgat, G., and Schneider, W., 1990 (spectral resolution 0.01 nm, T= 294 K); in: Keller-Rudek, H., Moortgat, G. K., Sander, R., and Sörensen, R.: The MPI-Mainz UV/VIS spectral atlas of gaseous molecules of atmospheric interest, Earth Syst. Sci. Data, 5, 365-373, doi: 10.5194/essd-5-365-2013, 2013.

Mérienne, M. F., Jenouvrier, A., and Coquart, B.: The $\mathrm{NO}_{2}$ absorption-spectrum. 1. Absorption cross-sections at ambienttemperature in the 300-500 nm region, J. Atmos. Chem., 20, 281-297, doi: 10.1007/BF00694498, 1995.

Min, K. E., Washenfelder, R. A., Dubé, W. P., Langford, A. O., Edwards, P. M., Zarzana, K. J., Stutz, J., Lu, K., Rohrer, F., Zhang, Y., and Brown, S. S.: A broadband cavity enhanced absorption spectrometer for aircraft measurements of glyoxal, methylglyoxal, nitrous acid, nitrogen dioxide, and water vapor, Atmos. Meas. Tech., 9, 423-440, doi: 10.5194/amt-9-423-2016, 2016.

Nakashima, Y., and Sadanaga, Y.: Validation of in situ measurements of atmospheric nitrous acid using incoherent broadband cavity-enhanced absorption spectroscopy, Analyst. Sci., 33, 519-524, doi: 10.2116/analsci.33.519, 2017.

Nehr, S., Bohn, B., Dorn, H. P., Fuchs, H., Häseler, R., Hofzumahaus, A., Li, X., Rohrer, F., Tillmann, R., and Wahner, A.: Atmospheric photochemistry of aromatic hydrocarbons: OH budgets during SAPHIR chamber experiments, Atmos. Chem. Phys., 14, 6941-6952, doi: 10.5194/acp-14-6941-2014, 2014.

Nussbaumer, C. M., Parchatka, U., Tadic, I., Bohn, B., Marno, D., Martinez, M., Rohloff, R., Harder, H., Kluge, F., Pfeilsticker, K., Obersteiner, F., Zöger, M., Doerich, R., Crowley, J. N., Lelieveld, J., and Fischer, H.: New photolytic converter for improving aircraft measurements of $\mathrm{NO}_{2}$ via chemiluminescence, Atmos. Meas. Tech. Discuss. [preprint in review], doi: 10.5194/amt-2021-180, 2021.

Oms, M. T., Jongejan, P. A. C., Veltkamp, A. C., Wyers, G. P., and Slanina, J.: Continuous monitoring of atmospheric HCl, $\mathrm{HNO}_{2}, \mathrm{HNO}_{3}$, and $\mathrm{SO}_{2}$, by wet-annular denuder air sampling with on-line chromatographic analysis, Int. J. Environ. Anal. Chem., 62, 207-218, doi: 10.1080/03067319608028134, 1996.

Press, W. H., Flannery, T. S. and Vetterling, W. T.: Numerical Recipes: The Art of Scientific Computing, Cambridge U. Press, 1986, pp. 51 and 670.

Ramazan, K. A., Syomin, D., and Finlayson-Pitts, B. J.: The photochemical production of HONO during the heterogeneous hydrolysis of $\mathrm{NO}_{2}$, Phys. Chem. Chem. Phys., 6, 3836-3843, doi: 10.1039/B402195A, 2004.

Reisinger, A. R.: Observations of $\mathrm{HNO}_{2}$ in the polluted winter atmosphere: possible heterogeneous production on aerosols. Atmos. Environ., 34, 3865-3874, doi: 10.1016/S1352-2310(00)00179-5, 2000. 
https://doi.org/10.5194/amt-2021-291

Preprint. Discussion started: 22 November 2021

(c) Author(s) 2021. CC BY 4.0 License.
Atmospheric

Measurement

Techniques

Discussions

Roberts, J. M., and Bertman, S. B.: The thermal decomposition of peroxy acetic nitric anhydride (PAN) and peroxymethacrylic nitric anhydride (MPAN), Int. J. Chem. Kinetics, 24, 297-307, doi: 10.1002/kin.550240307, 1992.

Rodenas, M., Munoz, A., Alacreu, F., Brauers, T., Dorn, H. P., Kleffmann, J., and Bloss, W.: Assessment of HONO Measurements: The FIONA Campaign at EUPHORE, in: Disposal of Dangerous Chemicals in Urban Areas and Mega Cities: Role of Oxides and Acids of Nitrogen in Atmospheric Chemistry, Eds. Barnes, I., and Rudzinski, K. J., Springer, Dordrecht, pp. 45-58, 2013.

Rodgers, M. O., and Davis, D. D.: A UV-photofragmentation laser-induced fluorescence sensor for detection of HONO, Environ. Sci. Tech., 23, 1106-1112, doi: 10.1021/es00067a007, 1989.

Rohrer, F., and Brüning, D.: Surface $\mathrm{NO}$ and $\mathrm{NO}_{2}$ mixing ratios measured between 30 degrees- $\mathrm{N}$ and 30 degrees-S in the Atlantic region, J. Atmos. Chem., 15, 253-267, doi: 10.1007/BF00115397, 1992.

Rohrer, F., Bohn, B., Brauers, T., Bruning, D., Johnen, F. J., Wahner, A., and Kleffmann, J.: Characterisation of the photolytic HONO-source in the atmosphere simulation chamber SAPHIR, Atmos. Chem. Phys., 5, 2189-2201, doi: 10.5194/acp5-2189-2005, 2005.

Ruth, A. A., Dixneuf, S., Raghunandan, R.: Broadband cavity-enhanced absorption Spectroscopy with incoherent light, in: Cavity enhanced spectroscopy and sensing, Eds. Gagliardi, G., and Loock, H. P., Springer Series in Optical Sciences, 179, 485-517, doi: 10.1007/978-3-642-40003-2., 2014.

Saiz-Lopez, A., Plane, J. M. C., McFiggans, G., Williams, P. I., Ball, S. M., Bitter, M., Jones, R. L., Hongwei, C., and Hoffmann, T.: Modelling molecular iodine emissions in a coastal marine environment: the link to new particle formation, Atmos. Chem. Phys., 6, 883-895, doi: 10.5194/acp-6-883-2006, 2006.

Schiller, C. L., Locquiao, S., Johnson, T. J., and Harris, G. W.: Atmospheric measurements of HONO by tunable diode laser absorption spectroscopy, J. Atmos. Chem., 40, 275-293, doi: 10.1023/A:1012264601306, 2001.

Scharko, N. K., Berke, A. E., and Raff, J. D.: Release of nitrous acid and nitrogen dioxide from nitrate photolysis in acidic aqueous solutions, Environ. Sci. Tech., 48, 11991-12001, doi: 10.1021/es503088x, 2014.

Simon, P. K., and Dasgupta, P. K.: Continuous automated measurement of gaseous nitrous and nitric acids and particulate nitrite and nitrate, Environ. Sci. Tech., 29, 1534-1541, doi: 10.1021/es00006a015, 1995.

Spataro, F., and Ianniello, A.: Sources of atmospheric nitrous acid: State of the science, current research needs, and future prospects, J. Air Waste Man. Assoc., 64, 1232-1250, doi: 10.1080/10962247.2014.952846, 2014.

Spindler, G., Hesper, J., Brüggemann, E., Dubois, R., Müller, T., and Herrmann, H.: Wet annular denuder measurements of nitrous acid: laboratory study of the artefact reaction of $\mathrm{NO}_{2}$ with $\mathrm{S}(\mathrm{IV})$ in aqueous solution and comparison with field measurements, Atmos. Environ., 37, 2643-2662, doi: 10.1016/S1352-2310(03)00209-7, 2003.

Staffelbach, T., Neftel, A., and Horowitz, L. W.: Photochemical oxidant formation over southern Switzerland. 2. Model results, J. Geophys. Res.-Atmos., 102, 23363-23373, doi: 10.1029/97JD00932, 1997.

Stemmler, K., Ammann, M., Donders, C., Kleffmann, J., and George, C.: Photosensitized reduction of nitrogen dioxide on humic acid as a source of nitrous acid, Nature, 440, 195-198, doi: 10.1038/nature04603, 2006. 
https://doi.org/10.5194/amt-2021-291

Preprint. Discussion started: 22 November 2021

(c) Author(s) 2021. CC BY 4.0 License.
Atmospheric

Measurement

Techniques

Discussions

Stutz, J., Kim, E. S., Platt, U., Bruno, P., Perrino, C., and Febo, A.: UV-visible absorption cross sections of nitrous acid, J. Geophys. Res.-Atmos., 105, 14585-14592, doi: 10.1029/2000JD900003, 2000.

605

Stutz, J., Oha, H.-J., Whitlow, S. I., Anderson, C., Dibb, J. E., Flynn, J. H., Rappenglück, B., and Lefer, B.: Simultaneous DOAS and mist-chamber IC measurements of HONO in Houston, TX, Atmos. Environ., 44, 4090-4098, doi: 10.1016/j.atmosenv.2009.02.003, 2010.

Takenaka, N., Terada, H., Oro, Y., Hiroi, M., Yoshikawa, H., Okitsu, K., and Bandow, H.: A new method for the measurement of trace amounts of HONO in the atmosphere using an air-dragged aqua-membrane-type denuder and fluorescence

Thalman, R., and Volkamer, R.: Inherent calibration of a blue LED-CE-DOAS instrument to measure iodine oxide, glyoxal, methyl glyoxal, nitrogen dioxide, water vapour and aerosol extinction in open cavity mode, Atmos. Meas. Tech., 3 , 1797-1814, doi: 10.5194/amt-3-1797-2010, 2010.

Varma, R. M., Venables, D. S., Ruth, A. A., Heitmann, U., Schlosser, E., and Dixneuf, S.: Long optical cavities for open-path monitoring of atmospheric trace gases and aerosol extinction, Appl. Opt., 48, B159-B171, doi: 10.1364/AO.48.00B159, 2009.

Varma, R. M., Ball, S. M., Brauers, T., Dorn, H. P., Heitmann, U., Jones, R. L., Platt, U., Pöhler, D., Ruth, A. A., Shillings, A. J. L., Thieser, J., Wahner, A., and Venables, D. S.: Light extinction by secondary organic aerosol: an intercomparison of three broadband cavity spectrometers, Atmos. Meas. Tech., 6, 3115-3130, doi: 10.5194/amt-6-3115-2013, 2013.

Vogel, B., Vogel, H., Kleffmann, J., and Kurtenbach, R.: Measured and simulated vertical profiles of nitrous acid - Part II. Model simulations and indications for a photolytic source, Atmos. Environ., 37, 2957-2966, doi: 10.1016/S13522310(03)00243-7, 2003.

Wang, L. M., and Zhang, J. S.: Detection of nitrous acid by cavity ring down spectroscopy, Environ. Sci. Tech., 34, 42214227, doi: 10.1021/es0011055, 2000.

Washenfelder, R. A., Langford, A. O., Fuchs, H., and Brown, S. S.: Measurement of glyoxal using an incoherent broadband cavity enhanced absorption spectrometer, Atmos. Chem. Phys., 8, 7779-7793, doi: 10.1021/es0011055, 2008.

Wisthaler, A., Apel, E. C., Bossmeyer, J., Hansel, A., Junkermann, W., Koppmann, R., Meier, R., Müller, K., Solomon, S. J., Steinbrecher, R., Tillmann, R., and Brauers, T.: Technical Note: Intercomparison of formaldehyde measurements at the atmosphere simulation chamber SAPHIR, Atmos. Chem. Phys., 8, 2189-2200, doi: 10.5194/acp-8-2189-2008, 2008.

Wu, T., Zhao, W., Chen, W., Zhang, W., and Gao, X.: Incoherent broadband cavity enhanced absorption spectroscopy for in situ measurements of $\mathrm{NO}_{2}$ with a blue light emitting diode, Appl. Phys. B - Lasers and Optics, 94, 85-94, doi: 10.1007/s00340-008-3308-8, 2009.

Wu, T., Chen, W., Fertein, E., Cazier, F., Dewaele, D., and Gao, X.: Development of an open-path incoherent broadband 635 cavity-enhanced spectroscopy based instrument for simultaneous measurement of $\mathrm{HONO}$ and $\mathrm{NO}_{2}$ in ambient air, Appl. Phys. B - Lasers and Optics, 106, 501-509, doi: 10.1007/s00340-011-4818-3, 2012. 
Yi, H., Cazaunau, M., Gratien, A., Michoud, V., Pangui, E., Doussin, J.-F., and Chen, W.: Intercomparison of IBBCEAS, NitroMAC and FTIR analyses for $\mathrm{HONO}, \mathrm{NO}_{2}$ and $\mathrm{CH}_{2} \mathrm{O}$ measurements during the reaction of $\mathrm{NO}_{2}$ with $\mathrm{H}_{2} \mathrm{O}$ vapour in the simulation chamber CESAM, Atmos. Meas. Tech., 14, 5701-5715, doi: 10.5194/amt-14-5701-2021, 2021.

640 Zhou, X. L., Civerolo, K., Dai, H. P., Huang, G., Schwab, J., and Demerjian, K.: Summertime nitrous acid chemistry in the atmospheric boundary layer at a rural site in New York state, J. Geophys. Res.-Atmos., 107, D21.4590, doi: 10.1029/2001JD001539, 2002a.

Zhou, X. L., He, Y., Huang, G., Thornberry, T. D., Carroll, M. A., and Bertman, S. B.: Photochemical production of nitrous acid on glass sample manifold surface, Geophys. Res. Lett., 29, 1681, doi: 10.1029/2002GL015080, 2002 b.

645 Zhou, X. L., Gao, H. L., He, Y., Huang, G., Bertman, S. B., Civerolo, K., and Schwab, J.: Nitric acid photolysis on surfaces in low-NOx environments: Significant atmospheric implications, Geophys. Res. Lett., 30, 23.2217, doi: 10.1029/2003GL018620, 2003.

650

655

660

665

670 
https://doi.org/10.5194/amt-2021-291

Preprint. Discussion started: 22 November 2021

(c) Author(s) 2021. CC BY 4.0 License.
Atmospheric Measurement

Techniques

Discussions

685 Table 1. Comparison of correlation plot data. $N$ : number of data points, $a$ and $b$ : regression coefficients, $\sigma(a)$ and and $\sigma(b)$ : bootstrap errors of the linear square fit $y=a+b x$ (where $y$ represent IBBCEAS data [pptv] and $x$ the data [pptv] by either LOPAP, CLS or PTRMS), $\mathbf{r}^{2}$ : Pearson linear correlation coefficients.

\begin{tabular}{|c|c|c|c|c|c|c|}
\hline date & $N$ & $a[p p t v]$ & $\sigma(a)[p p t v]$ & $\boldsymbol{B}$ & $\sigma(b)$ & $\mathbf{r}^{2}$ \\
\hline \multicolumn{7}{|c|}{ HONO: IBBCEAS vs. LOPAP } \\
\hline 11 July & 553 & 11.1 & 2.5 & 0.915 & 0.013 & 0.8844 \\
\hline 12 July & 360 & -0.3 & 1.3 & 0.883 & 0.017 & 0.8645 \\
\hline 5 Oct & 299 & -16.2 & 1.1 & 0.992 & 0.007 & 0.9885 \\
\hline 6 Oct & 394 & -26.1 & 2.9 & 1.020 & 0.013 & 0.9408 \\
\hline all 4 days & 1668 & -8.4 & 0.9 & 0.973 & 0.005 & 0.9489 \\
\hline \multicolumn{7}{|c|}{$\mathrm{NO}_{2}:$ IBBCEAS vs. CLS } \\
\hline 11 July & 708 & -157 & 11 & 1.085 & 0.012 & 0.9253 \\
\hline 12 July & 378 & -56 & 5 & 1.090 & 0.019 & 0.9415 \\
\hline 5 Oct & 531 & 15 & 7 & 1.050 & 0.011 & 0.9837 \\
\hline 6 Oct & 634 & 3 & 2 & 1.385 & 0.019 & 0.8786 \\
\hline all 4 days & 3011 & -29 & 3 & 1.031 & 0.007 & 0.9700 \\
\hline \multicolumn{7}{|c|}{ MACR: IBBCEAS vs. PTRMS } \\
\hline 11 July & 657 & 103 & 27 & 0.947 & 0.010 & 0.9623 \\
\hline
\end{tabular}



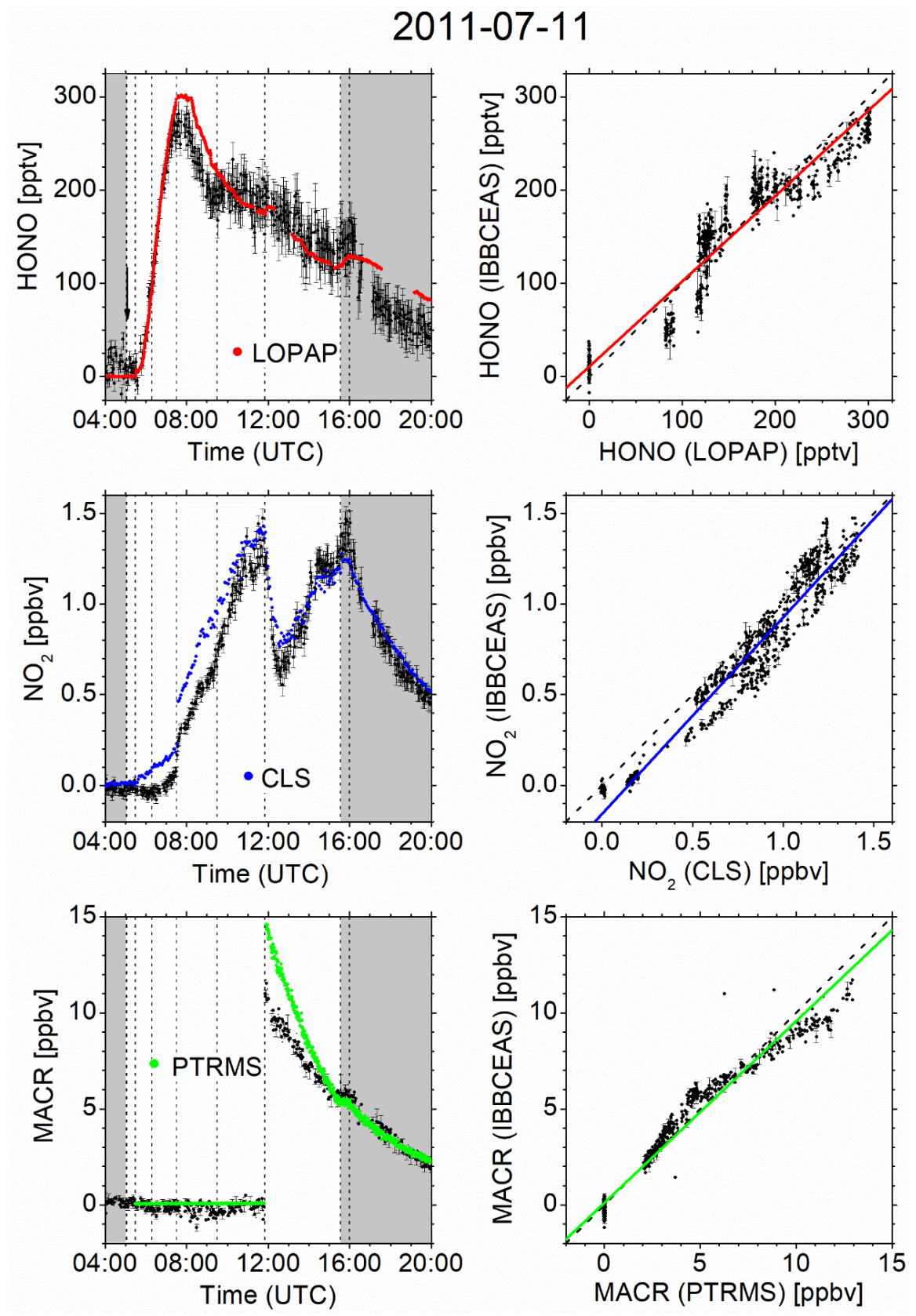

Figure 1: Left panels: Time-dependent HONO, NO2 and MACR mixing ratios measured by IBBCEAS (black trace) at SAPHIR on 11 July 2011. Dashed vertical lines indicate changes in the chamber conditions according to the experimental protocol: Overnight flushing of chamber with zero air stopped (5:03), roof opened (5:05), start of humidification (5:30), end of humidification (6:18), 40 ppbv O3 (7:30), 750 ppbv CO (09:30), MACR (11:51), roof closing (15:33), flushing with zero air started (16:00). IBBCEAS data taken in the near-UV region of the spectrum $(352-386 \mathrm{~nm}$ ) are compared to LOPAP (red), CLS (blue) and PTRMS (green) data. The vertical black arrow indicates the time when $I_{0}$ was measured (generally for 10 min). Right panels: Correlation plots of two instruments being compared against IBBCEAS. The dashed line represents the identity, the colored solid lines are linear regressions to the data. Results are listed in Table 1. 

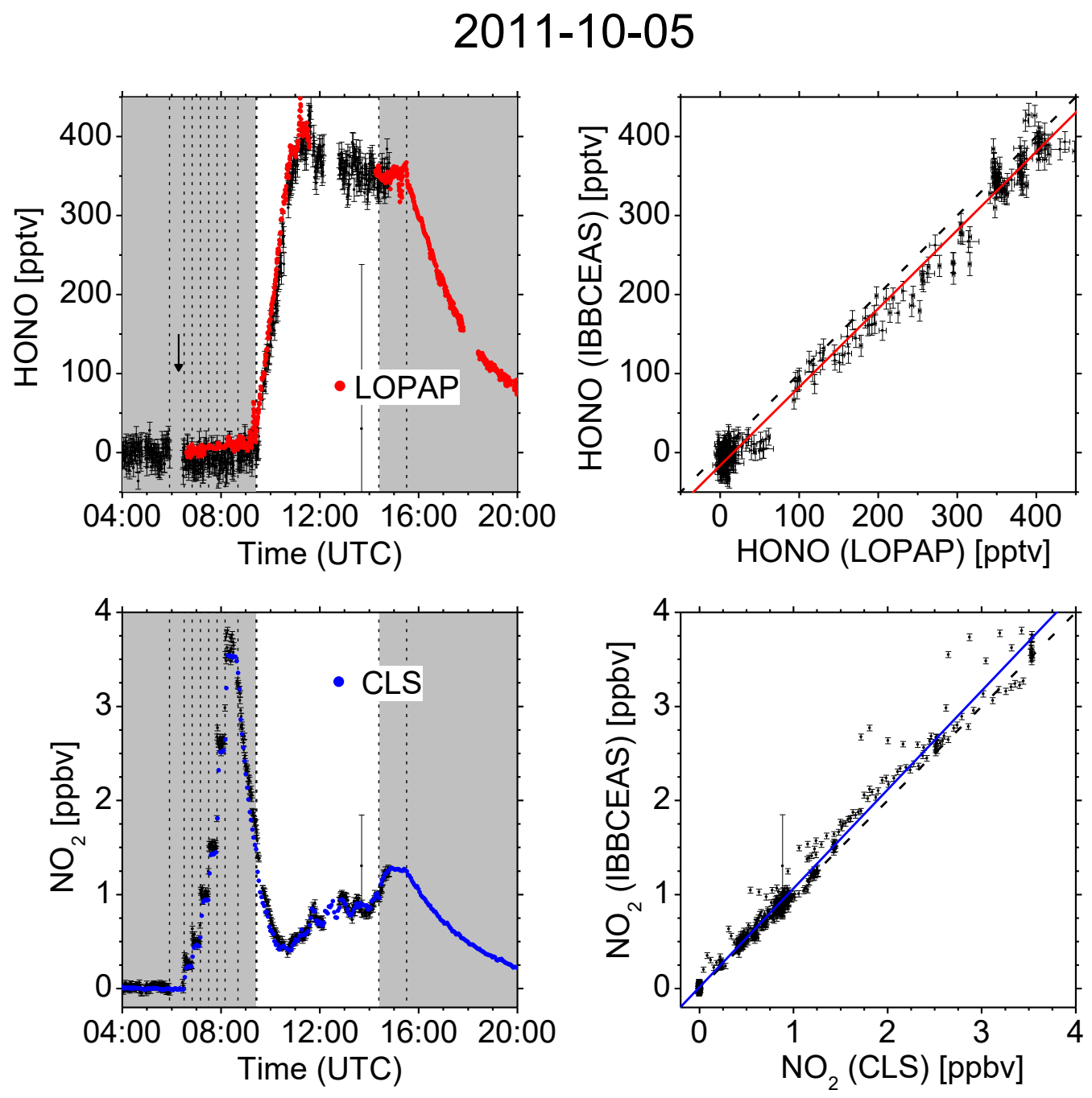

Figure 2: Left panels: Time-dependent HONO and $\mathrm{NO}_{2}$ mixing ratios measured at SAPHIR on 5 October 2011. Dashed vertical lines indicate changes in the chamber conditions according to the experimental protocol: Overnight flushing stopped (5:55), 250 pptv $\mathrm{NO}_{2}$ (6:30 and 6:50), 500 pptv $\mathrm{NO}_{2}$ (7:10 and 7:30), 1 ppbv $\mathrm{NO}_{2}$ (7:50 and 8:10), start humidification (8:41), stop humidification (9:25), roof opening (9:27), roof closing (14:23), flushing started (15:31). IBBCEAS data taken in the near-UV region of the spectrum (352$386 \mathrm{~nm}$ ) are compared to LOPAP (red) and CLS (blue). The vertical black arrow indicates the time when $I_{0}$ was measured (generally for $10 \mathrm{~min}$ ). Right panels: Correlation plots of two instruments being compared against IBBCEAS. The dashed line represents the identity, the colored solid lines are linear regressions to the data. Results are listed in Table 1. 

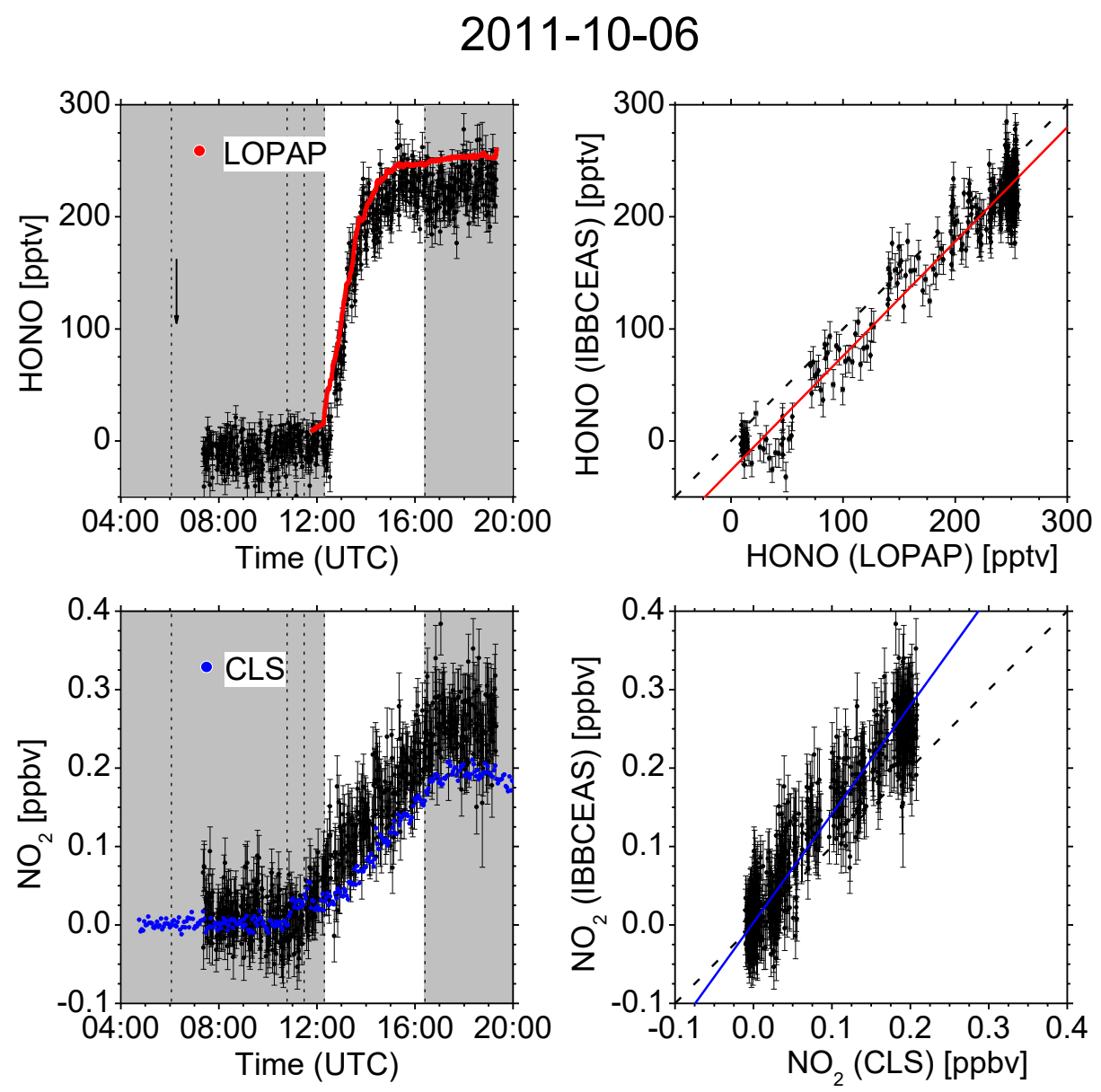

Figure 3: Left panels: Time-dependent HONO and $\mathrm{NO}_{2}$ mixing ratios measured at SAPHIR on 6 October 2011. Dashed vertical lines indicate changes in the chamber conditions according to the experimental protocol: Overnight flushing stopped (6:04), start humidification (10:47), stop humidification (11:29), roof opening (12:18), roof closing (16:24). IBBCEAS data taken in the near-UV region of the spectrum $(352-386 \mathrm{~nm}$ ) are compared to LOPAP (red) and CLS (blue) data. The vertical black arrow indicates the time when $I_{0}$ was measured (generally for $10 \mathrm{~min}$ ). Right panels: Correlation plots of two instruments being compared against IBBCEAS. The dashed line represents the identity, the colored solid lines are linear regressions to the data. Results are listed in Table 1. 


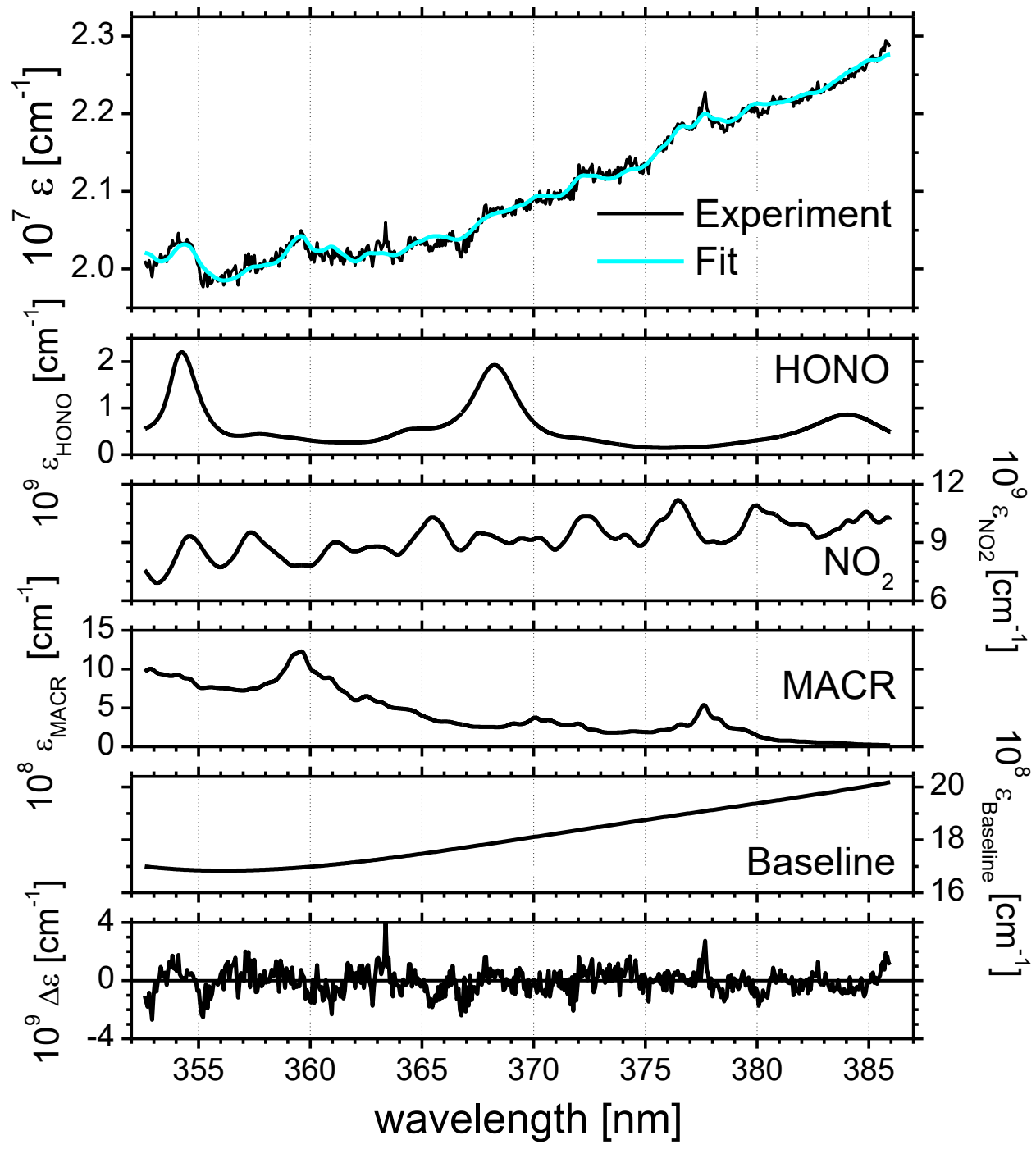

Figure 4: Example of the extinction coefficient spectrum, $\varepsilon(\lambda)$, measured with IBBCEAS at SAPHIR in the wavelength range 352$386 \mathrm{~nm}$ with an integration time of $1 \mathrm{~min}$, taken at 13:00 hrs on 11 July 2011. Uppermost panel: measured extinction (black), fit of eq (1) to the extinction (cyan). Lowermost panel: Absolute fit residuals $\Delta \varepsilon=\varepsilon$ fit $-\varepsilon$ exp. HONO, NO 2 and MACR mixing ratios were retrieved as $n_{\mathrm{HONO}}=\mathbf{0 . 1 6 0} \mathrm{ppbv}, n_{\mathrm{NO} 2}=\mathbf{0 . 5 8 6} \mathrm{ppbv}$ and $n_{\mathrm{MACR}}=\mathbf{8 . 0 5 5} \mathrm{ppbv}$, respectively. The corresponding contributions and the polynomial baseline are shown in the middle panels. The absolute wavelength scale was calibrated with a low-pressure Ne pen ray lamp. $\mathrm{O}_{2}-\mathrm{O}_{2}$ absorption at $\sim 360$ and $\sim 380 \mathrm{~nm}$ not relevant as evident from the residuals in the lowermost panel. 

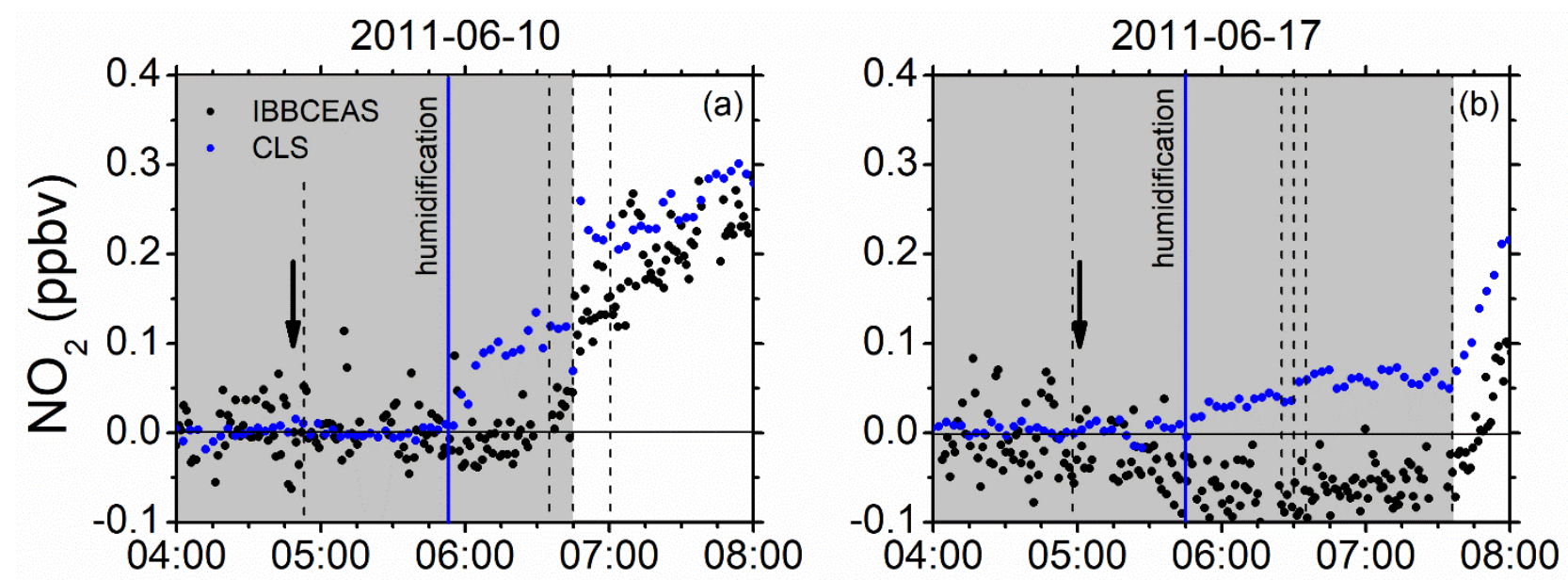

Figure 5: Examples of the small increase of $\mathrm{NO}_{2}$ mixing ratios upon humidification in the dark chamber measured with CLS (blue dots) in comparison to those measured with IBBCEAS (black dots): (a) 10 June 2011: CO 2 addition (4:53), start of humidification (5:52 - vertical solid blue line), ozone addition (6:36), roof opened (6:46), isoprene addition (7:01). (b) 17 June 2011: Flushing of chamber stopped (04:58), start of humidification (05:45), end of humidification (06:25), $\mathrm{O}_{3}$ addition (06:30) in dark chamber, CO addition (06:35), roof opened (07:36). Vertical solid arrows indicate the time of the zeroing measurement $\left(I_{0}\right)$. 
https://doi.org/10.5194/amt-2021-291

Preprint. Discussion started: 22 November 2021

(c) Author(s) 2021. CC BY 4.0 License.

(c) (i)
Atmospheric Measurement

Techniques

Discussions
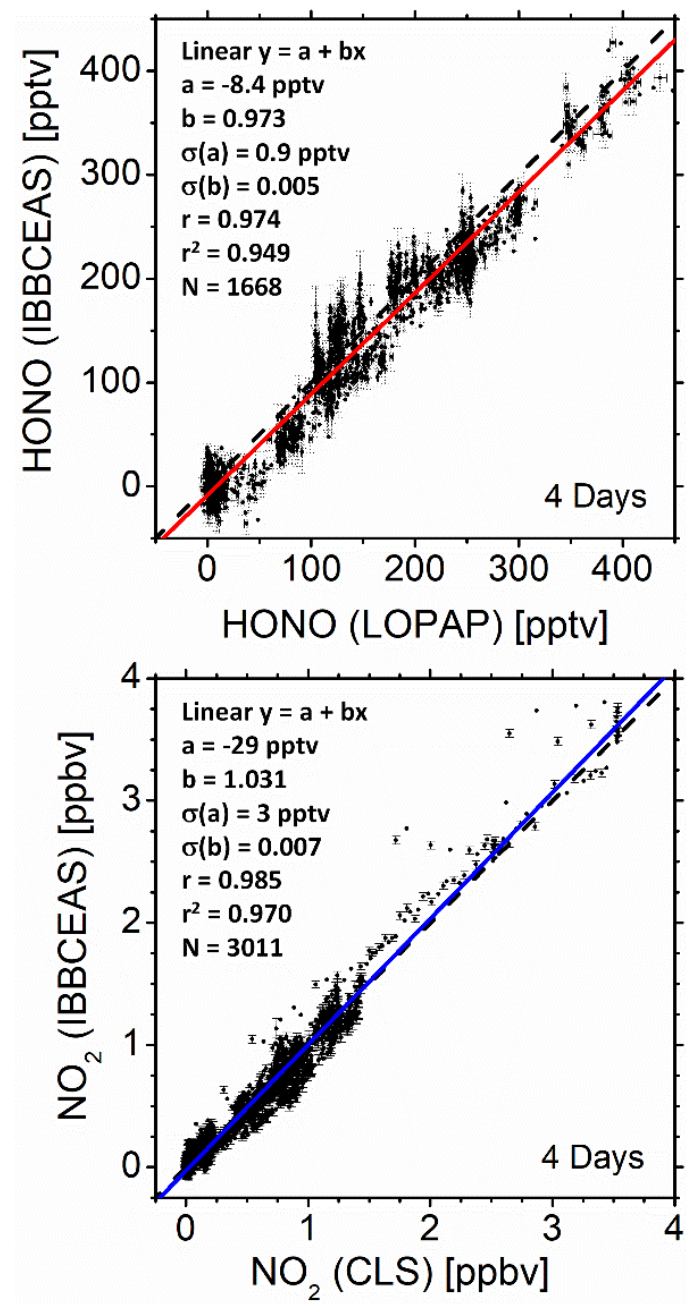

750 Figure 6: Correlation plots of two instruments of the entire data set from the intercomparison. The dashed line represents the identity, the coloured solid lines are linear regressions to the data (see also Table 1). 